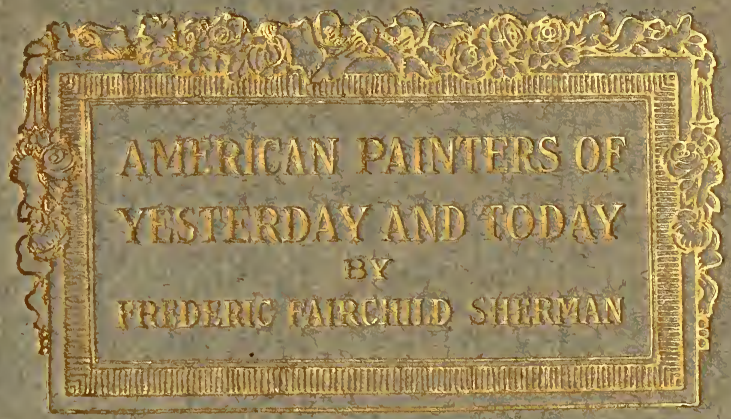




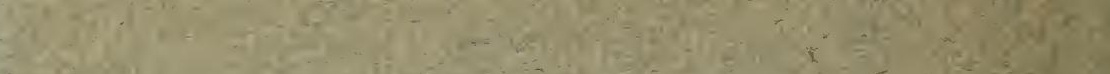
1.

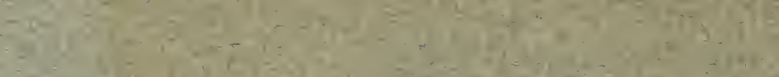

ais

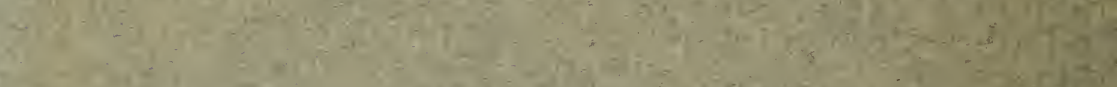

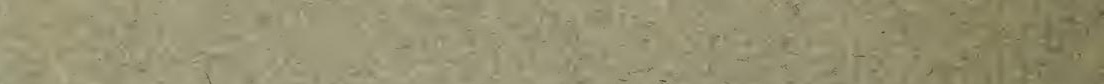

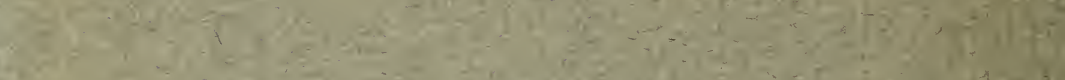

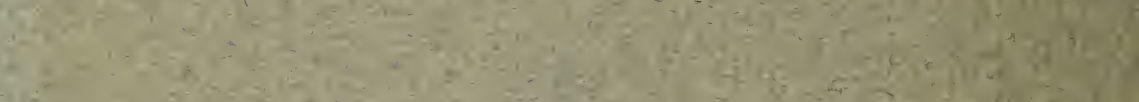

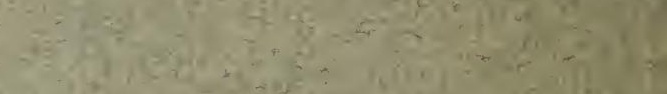

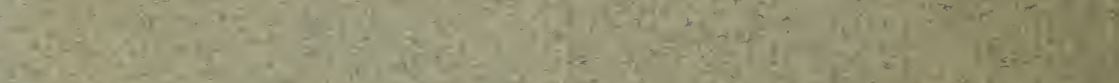

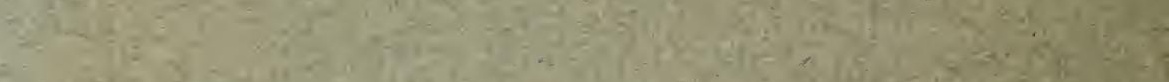

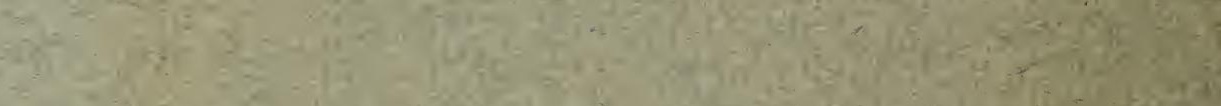

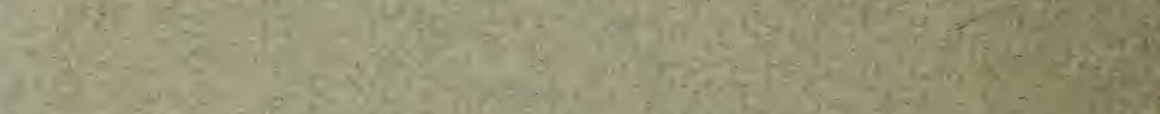

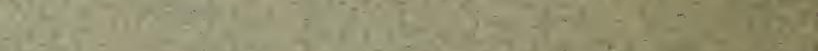

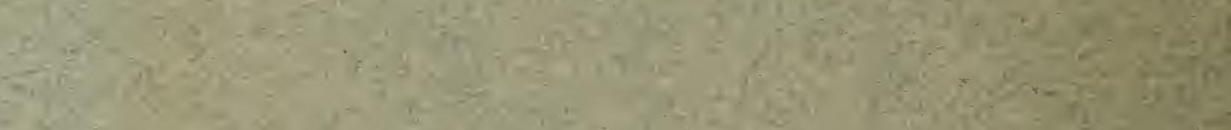

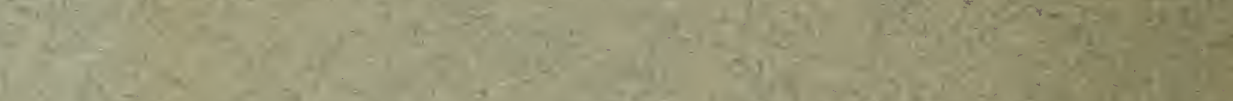

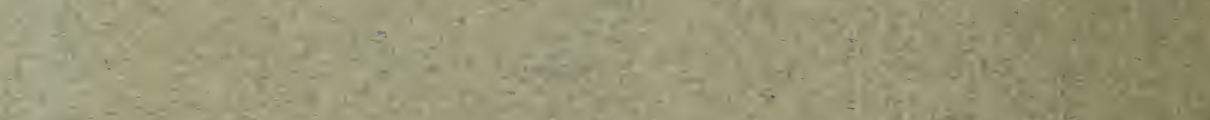

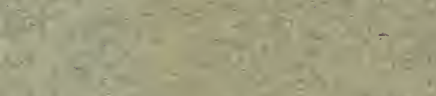

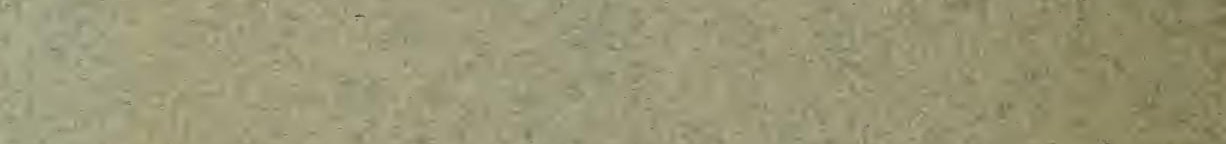

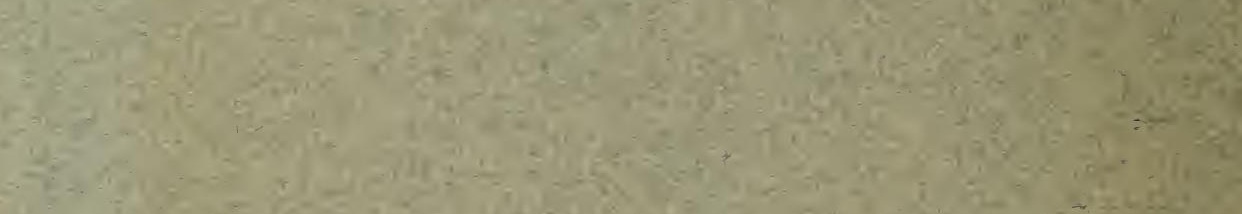

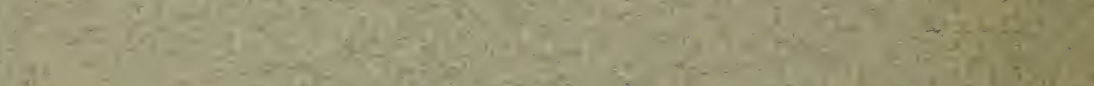

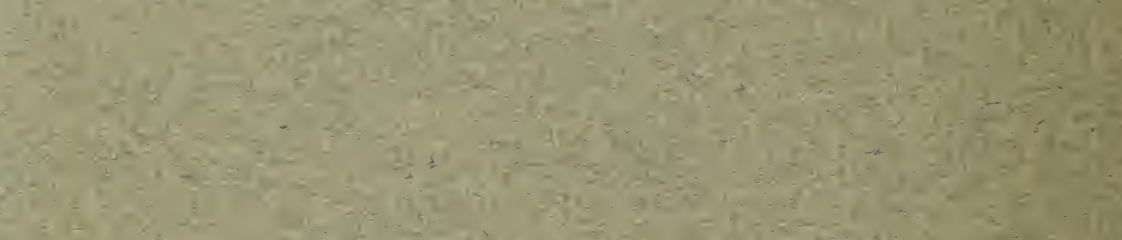

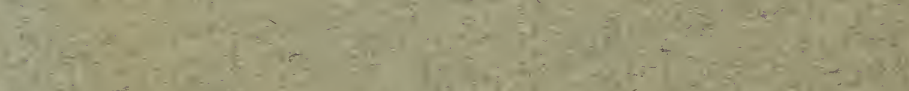

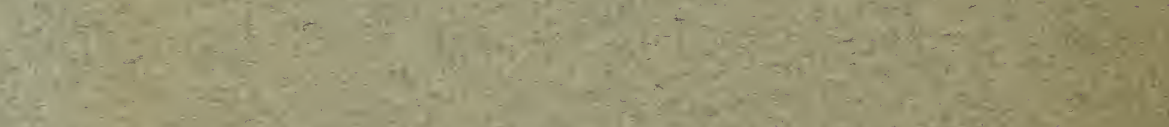

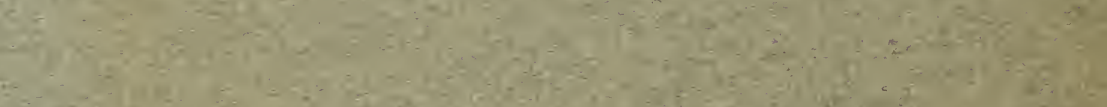

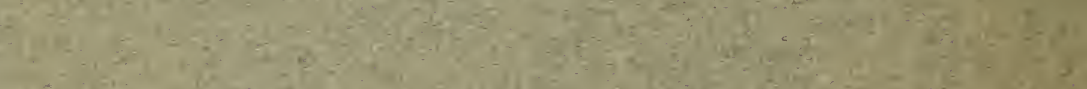

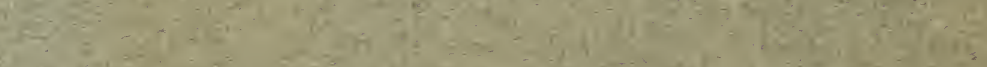




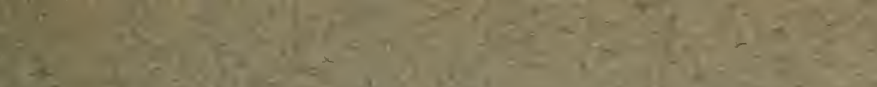

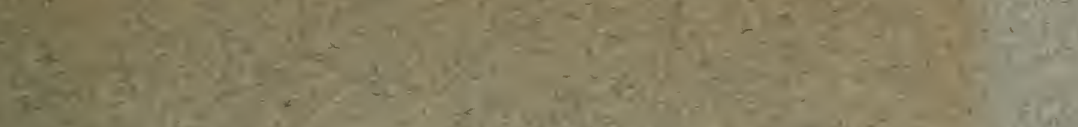

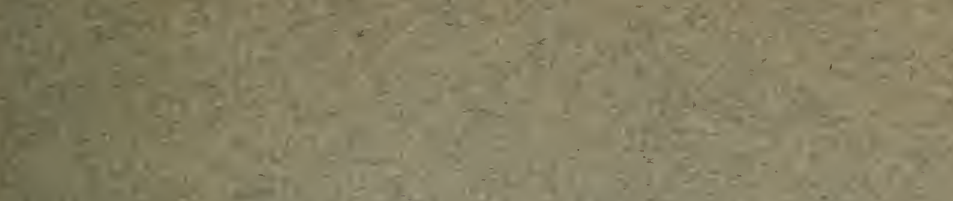

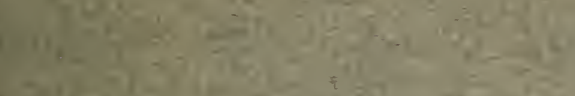

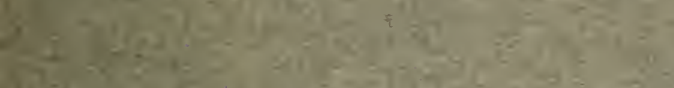

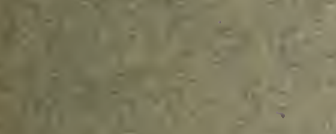

$p=282$

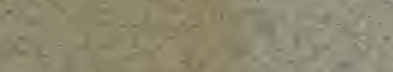

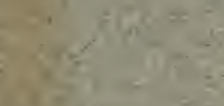

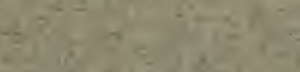

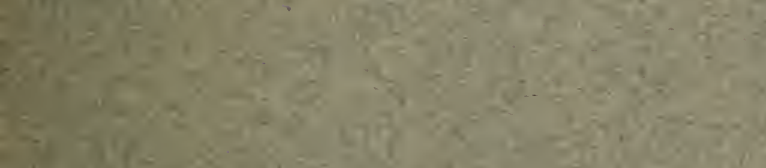
$-36$

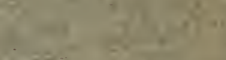

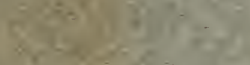

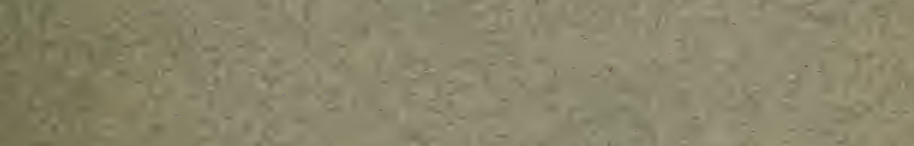

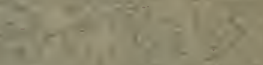
Din $\sin ^{2}$

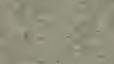



WEET 




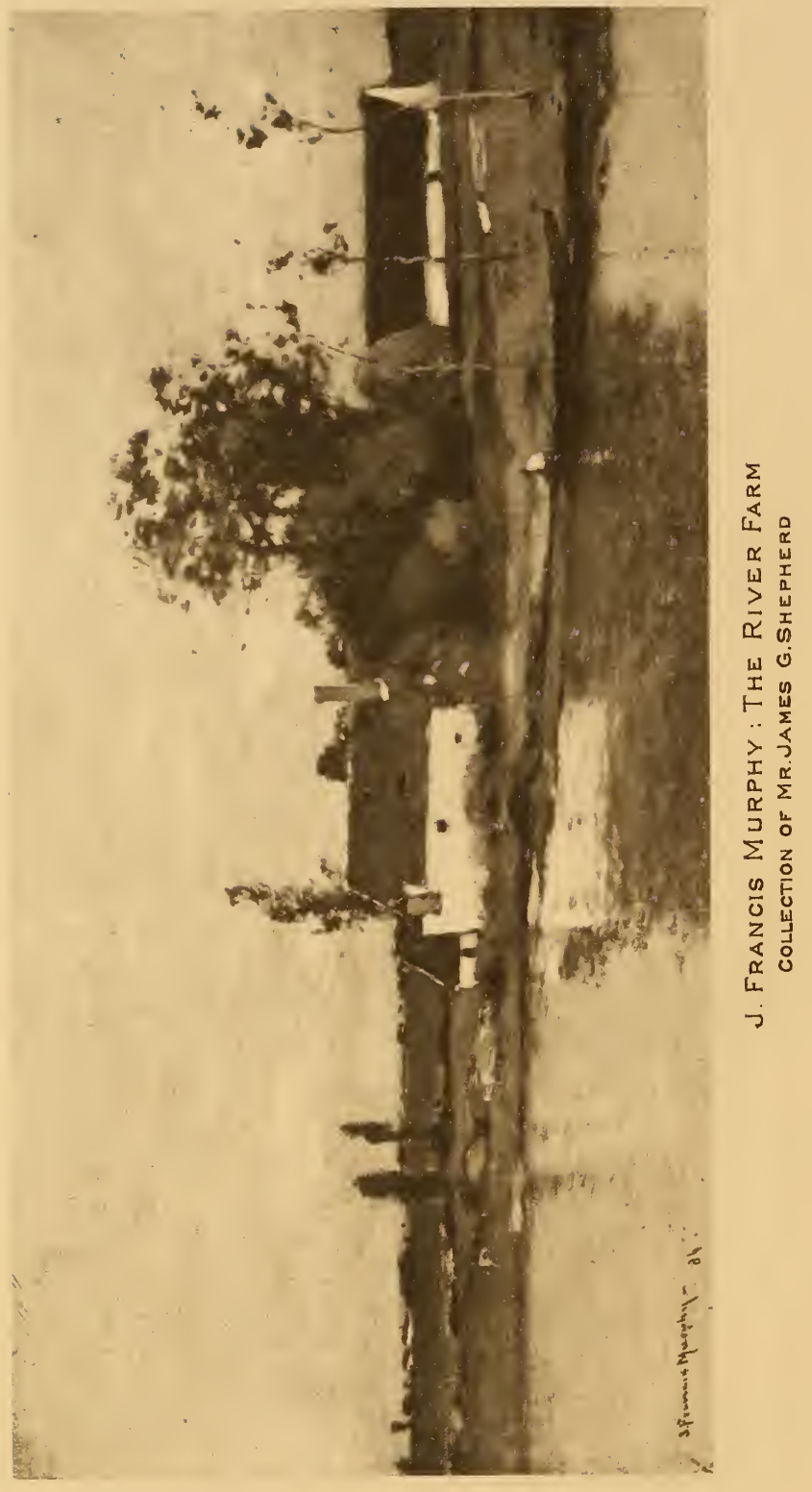




\title{
AMERICAN PAINTERS OF YESTERDAY AND TODAY
}

\author{
BY \\ FREDERIC FAIRCHILD SHERMAN
}
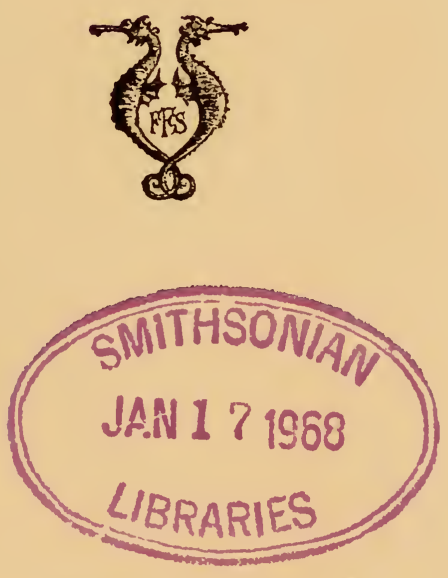

NEW YORK

PRIVATELY PRINTED

MCMXIX 
Copyright, 1919, by

Frederic Fairchild Sherman

7102460501 
$\begin{aligned} \text { TO MY FRIEND } & \text { FRI } \\ \text { DOROTHEA } & \text { A. DREIER }\end{aligned}$ 



\section{CONTENTS}

Miniature Landscapes by J. Francis Murphy . . . 3

The Landscape of Dwight W. Tryon . . . . . . I3

Four Figure Pictures by George Fuller . . . . . 2 I

Early Oil Paintings by Winslow Homer . . . . 29

Figure Pictures by Wyatt Eaton ....... . 39

Arthur B. Davies. . . . . . . . . . . . . . . . 47

Early Genre Pictures by Harry W. Watrous . . 55

Benjamin West............... 63 



\section{ILLUSTRATIONS}

\section{J. FRANCIS MURPHY}

THe River Farm . . . . . . Frontispiece

TwILIGHT . . . . . . . . . . 6

Late SePTEMber $\ldots \ldots \ldots$

Golden Autumn . . . . . . . . . . . . 8

DWIGHT W. TRYON

Glastonbury Meadows . . . . . . . . . . . I4 $_{4}$

Cernay la Ville . . . . . . . . . . . . I4

Early Morning, SePtember . . . . . . . 16

TwiLight, November . . . . . . . . . 18

GEORGE FULLER

THE RoMANY GIRL . . . . . . . . . . . 22

WinIFRED DYSART . . . . . . . . . . 22

THE QuAdROON ............... 22

PsYCHE ................... 22

WINSLOW HOMER

HAYMAKING . . . . . . . . . . . . . 29

The Song of the Lark ......... 30

A FRENCH FARM . . . . . . . . . . 30

Prout's NeCK . . . . . . . . . . . . . . . . 34

ix 


\section{WYATT EATON}

Portrait of William Cullen Bryant .... . 40 Ariadne . . . . . . . . . . . . . . 42 LAssitude ............... . . . 42

REVERIE ............... . . 42

ARTHUR B. DAVIES

Girl at the Fountain. . . . . . . . . . . 50

The Violin Girl . . . . . . . . . . . 50

Clothed in Dominion . . . . . . . . . . . 50

HARRY W. WATROUS

L'Addition . . . . . . . . . . . . 56

The Guitar Player . . . . . . . . . . . 56

RECORDS . . . . . . . . . . . . . 58

Lost . . . . . . . . . . . . . 58

BENJAMIN WEST

Portrait of John Sedley ... . . . . . . . 64

Portrait of a Gentleman . . . . . . . . . 66

The Envoys Returning from the Promised

LAND . . . . . . . . . . . . . . . . . . . . . . . . 68

Presentation of the Queen of Sheba at the

Court of King Solomon . . . . . . . . . 68 
MINIATURE LANDSCAPES

BY J. FRANCIS MURPHY 



\section{AMERICAN PAINTERS OF YESTERDAY AND TODAY}

\section{MINIATURE LANDSCAPES \\ BY J. FRANCIS MURPHY}

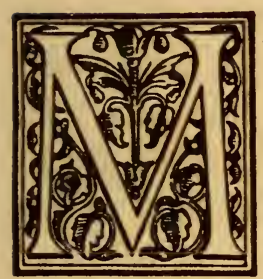

ERE size of itself has little or nothing to do with the greatness of any work of art, and yet many amateurs of today, especially in this country, persist in thinking and speaking only of large paintings as important pictures. Small as well as large paintings are sometimes important, and whoever habitually overlooks them necessarily misses a considerable measure of what is best in pictorial art.

Among our native landscape painters J. Francis Murphy has to his credit a sufficient number of landscapes in miniature of various periods to constitute a little gallery as representative as any that could be formed by gathering together a similar number of his large canvases. Quality, which is a very attractive element in his big pictures, his smaller works possess in a superlative degree. The natural intimacy of their appeal, however, is in no sense encom- 
passed at the expense of any sacrifice of spatial design or atmospheric envelopment which have so much to do with the authority as well as the beauty of his interpretation of nature. The best of his large pictures have their counterparts in miniature - little canvases that are just as truly and unmistakably masterpieces of landscape painting. One may study in them the characteristic technic of the artist, his sensitive subordination of insistent though inharmonious passages of color, and his discrimination and discretion in deliberately emphasizing the larger and finer aspects of linear design and chiaroscuro. In other words the best of these little landscapes are in every way as truly great pictures as the best of his large canvases.

Murphy is, I think, as Blakelock was, always at his best in his smallest and his largest pictures. The intermediate sizes seem not to afford area enough for his biggest efforts and yet to be too large to permit of his achieving in them that intimate touch which so sensibly enhances the charm of the smaller sizes. His little landscapes are more definitely representative and more truly expressive of nature herself, while his large landscapes oftener than not impress one as embodying rather his own feeling as he reacts to whatever mood it is he has chosen to interpret.

It is a curious characteristic of his art that while in his miniature canvases we often find various sub- 
sidiary elements of interest such as buildings, boats, figures and the like, the larger pictures seldom if ever present any variety of interest whatever, the whole canvas being deliberately devoted to the adequate expression of a single emotion, however elusive, and with no more of a foundation in the facts of nature than will suffice to frame the transitory loveliness of a moment. As a consequence of this method some of the large pictures seem relatively empty and sometimes, I think, rather uninteresting when the aerial envelope is insufficient of itself to clothe them in a beauty of its own or his effort to secure unusual quality is unsuccessful. The delicate gradation of values that counts for so much in his small canvases, if it fails to interpret his mood, becomes monotonous in the larger pictures. On the other hand all the evanescent loveliness of atmosphere is just as truly a part of his small as of his large paintings, only in them it is seemingly more a part of the scene itself and less an expression of the mood in which he worked.

I do not wish to convey the impression of being insensible to the merits of the large canvases - they are too obvious to permit of their being overlooked by anyone who is at all sensitive to what is most truly beautiful in contemporary American landscape art. In suggesting minor faults which one finds in some, I do not mean to imply that they are common even 
in the large canvases or that the smaller pictures which I have chosen to write about here are faultless. However, any inaccuracy in interpretation in a landscape of considerable dimensions is, simply because it involves so much in the way of mere representation, seemingly exaggerated, while a similar defect in a small painting is less likely to be discovered except as one studies it closely. I am not sure either that it is not true that in working a painter senses an inaccurate rendering in a small picture more often than in a large canvas, in the elaboration of which he is absorbed by subtleties of mood and emotion rather than by problems of actual representation. Thus Murphy's miniature landscapes have, I believe, a more definite aspect of reality while his larger pictures appeal to us more particularly because of their successful embodiment of spiritual values.

In the eighties and the nineties Murphy produced some of his finest works. As early as 1897 his interpretation shows a tendency toward that sensitive re-creation of delicate atmospheric harmonies which constitutes the great charm of his present work. The earlier pictures and especially the smaller of them are appreciably more realistic. They convey more of an idea of the actual beauty of nature unaltered by hazes, mistiness and half-lights. His present intention seems rather to embody in just these unsubstantial elements a sufficient emotional in- 


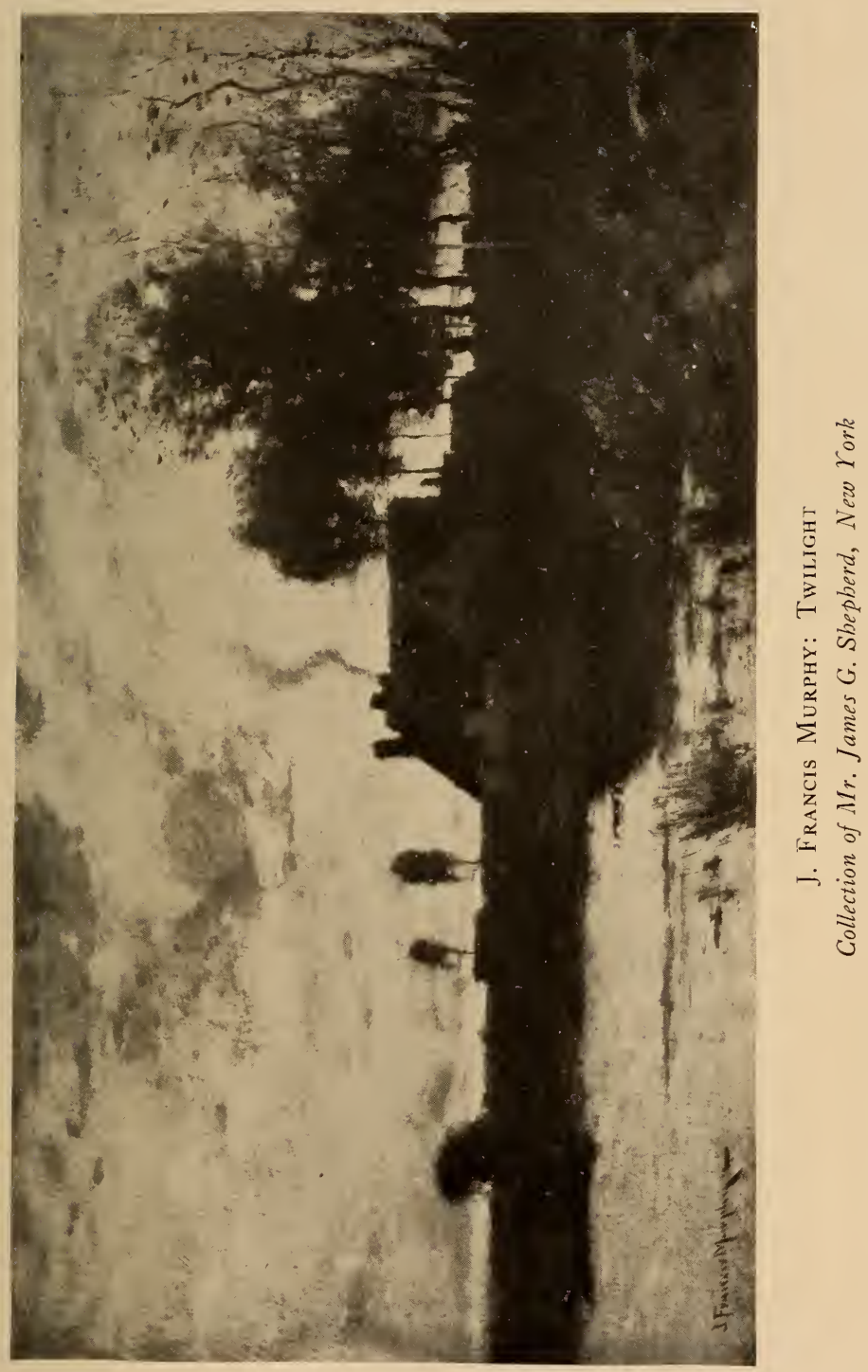





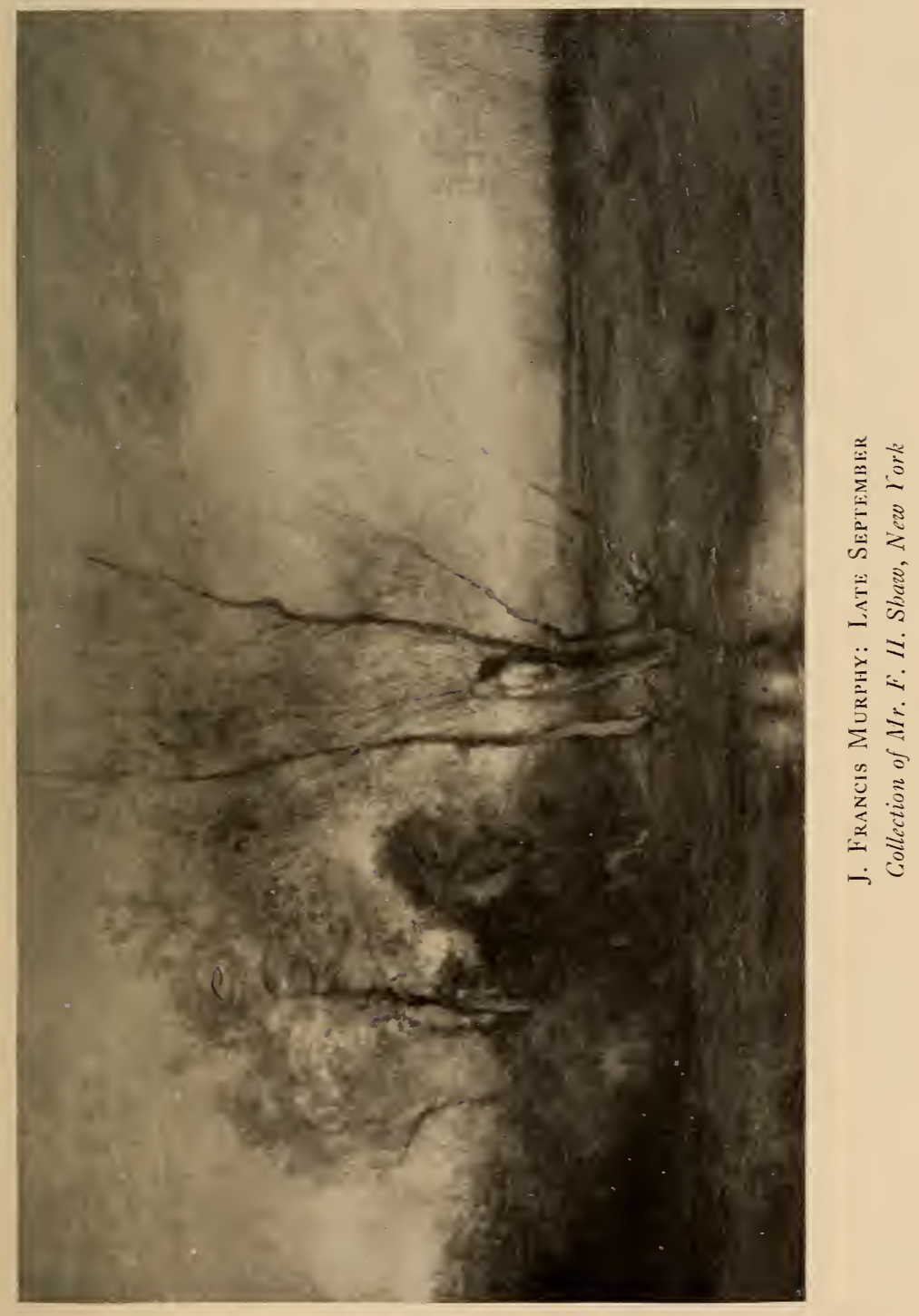



terest in the way of an expression of mood to satisfy one, regardless of the consequent lack of definition in the more elementary and substantial beauties of the earth. Inasmuch, however, as the mood in any given canvas is personal, it involves the integrity of the whole composition as an interpretation of nature, and leaves one eventually dissatisfied though perhaps unaware why. Only when he successfully interprets nature's moods are his later landscapes really great, because unmistakably true. The importance of these works is the greater because of the difficulty of the problem of producing in a convincing counterfeit of unsubstantial aerial envelope a reaction to an exquisite mood. Compared to the representation of the definite and obvious beauty of any scene from nature such a canvas is a real revelation of the possibilities of oil painting, and we therefore rightly estimate the best of them as the greatest of Murphy's paintings.

His earlier works are, however, more consistently satisfying because more generally successful. And their success is, I think, largely a matter of their being concerned chiefly with rendering the concrete rather than the abstract beauties of nature - the simple loveliness of certain scenes rather than those subtle atmospheric conditions in which the moods of nature are more sensibly felt, but which are infinitely more difficult to insinuate into an oil paint- 
ing. Indeed, considering his present problem, I do not so much wonder that some of his pictures fail to fully realize his intention as that such a number come so nearly to being entirely satisfactory in their embodiment of the spirit rather than the form of nature.

The River Farm, six by twelve inches, reproduced as the frontispiece to this volume, and the Twilight of approximately the same size, dated 1884 , are exquisite examples of the early period. The Late September of 1897 and the Golden Autumn of 1908, also very small canvases, show satisfactorily Murphy's development in the direction I have mentioned. The River Farm, with its houses and barns, haymow and boat at the water's edge, soft green meadow and distant fields, is a well-nigh perfect poem of country life. The cool blue of the sky where it shows through the soft white clouds is beautifully reflected in the placid waters of the river, together with all the charming detail of the foreground, and helps to make it a singularly attractive picture. The Twilight is a similar composition, the chief interest, however, being a fine rendering of the glamour of the afterglow. It is a sensitive interpretation, full of that subtlety of refinement which is so much a part of the artist's great gift as a landscape painter. These few works are sufficient, I think, to enable one to visualize his artistic devel- 


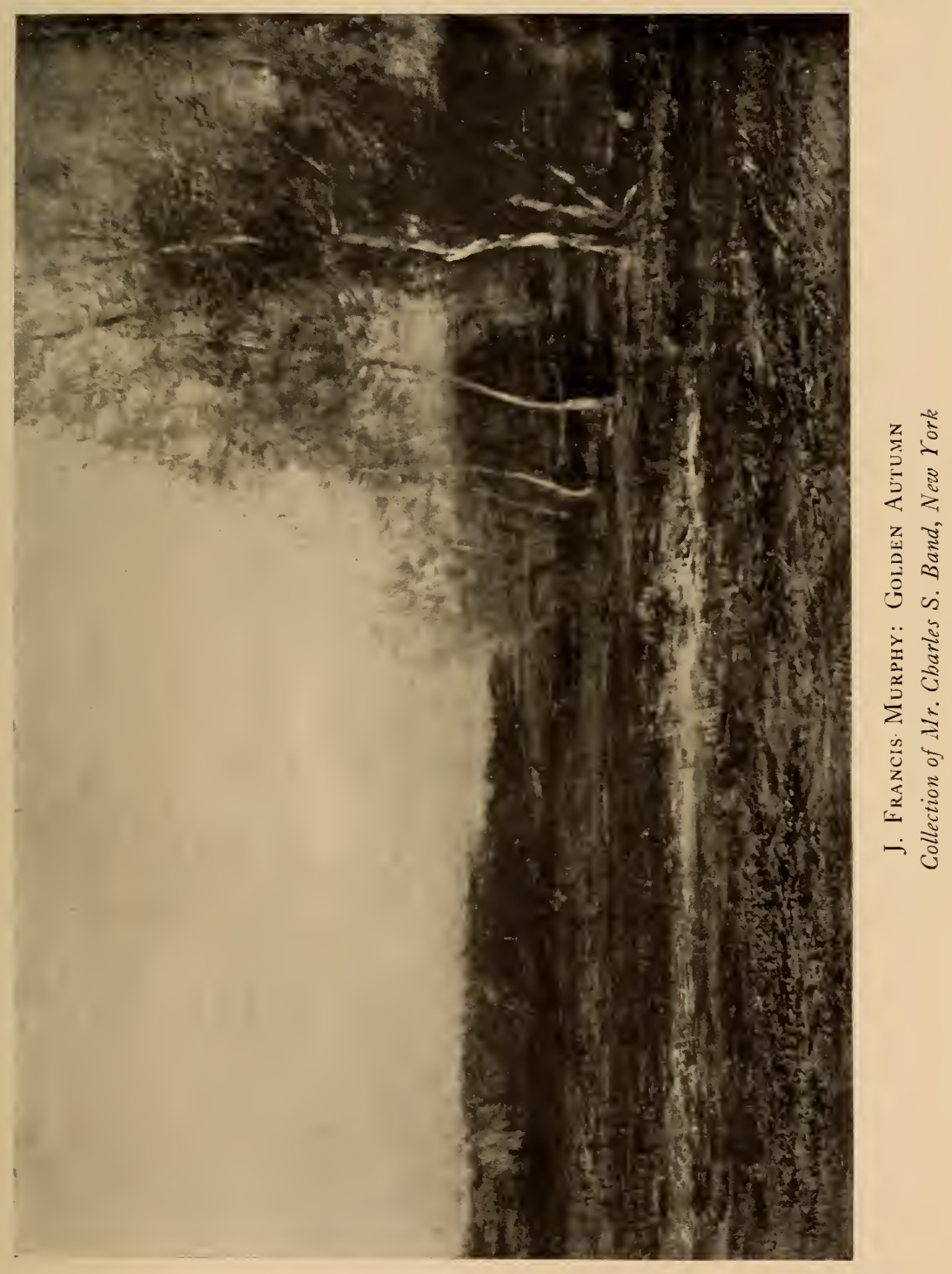



opment and at the same time they illustrate admirably the ideas of Murphy's art I have expressed in this essay.

I believe that if we stop to consider in what direction the development of landscape painting is now progressing it will be only to recognize it immediately in the way of increased attention given to atmospheric envelopment in which the painters of today are finding and giving to us a new revelation of beauty. It is Murphy's distinction to be one of the first as well as one of the best of our American exponents of this new type of landscape art. 

THE LANDSCAPE OF DWIGHT W. TRYON 



\section{THE LANDSCAPE OF DWIGHT W. TRYON}

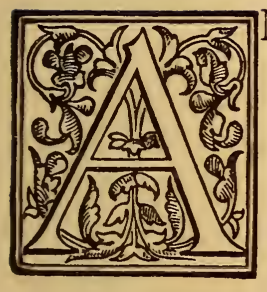

MERICAN LANDSCAPE of today is remarkable rather for fineness than for largeness of vision, for quality rather than for strength. A result of more careful study of the technic of pictorial art, it manifests itself in a facility unknown to the craftsmen of the Hudson River school, and in a tendency toward specialization in choice of subject which, with the possible exception of Wyant, was as foreign to practitioners of the period immediately following as it was to them. There ensues a measurable diminution of virility, together with an appreciable increase in subtlety of expression. The painter of today is more proficient than his predecessor and therefore his landscape is more precious and more precise in its interpretation of particular phases of nature. $\mathrm{He}$ lacks, however, the understanding that enabled a man like Inness, for instance, to visualize not alone one or two but many of her moods. It is a natural consequence of a more perfect technical training, the earlier artist, self-taught, inventing an imperfect method to express the big thing that powerfully 
moved him; the later, equipped with a superior style, intrigued by the elusiveness of certain lovely effects which he never tires of trying to transfer to his canvas. In the first instance the painter tries for a technic worthy of his subject, in the second for a subject worthy of his technic.

The development of American landscape has been singularly steady and consistent. That of Inness, Wyant, and Martin is obviously founded upon that of Bierstadt, Durand, and Kensett, and that of Tryon and Murphy is no less plainly the outcome of theirs. It has been a case at each step forward of the younger artist taking up the formula of his immediate predecessor, refining upon it and adapting it more perfectly to the emotional significance of the subject. Bierstadt is grandiose, but undisturbed by the human element that obstructs the grandeur of Cole; Martin and Inness discard the panoramic and the photographic, and in their lifetime our landscape first becomes truly significant in that it embodies feeling as well as representation. With Tryon it assumes a new intimacy through a harmonious emphasis of certain subtleties.

Tryon's landscape, besides being intimate, which it might be without necessarily being in any sense significant, is very poetic. Its poetry is that of an acknowledged precision, but it is no less authentic on that account and patently more perfect. The 


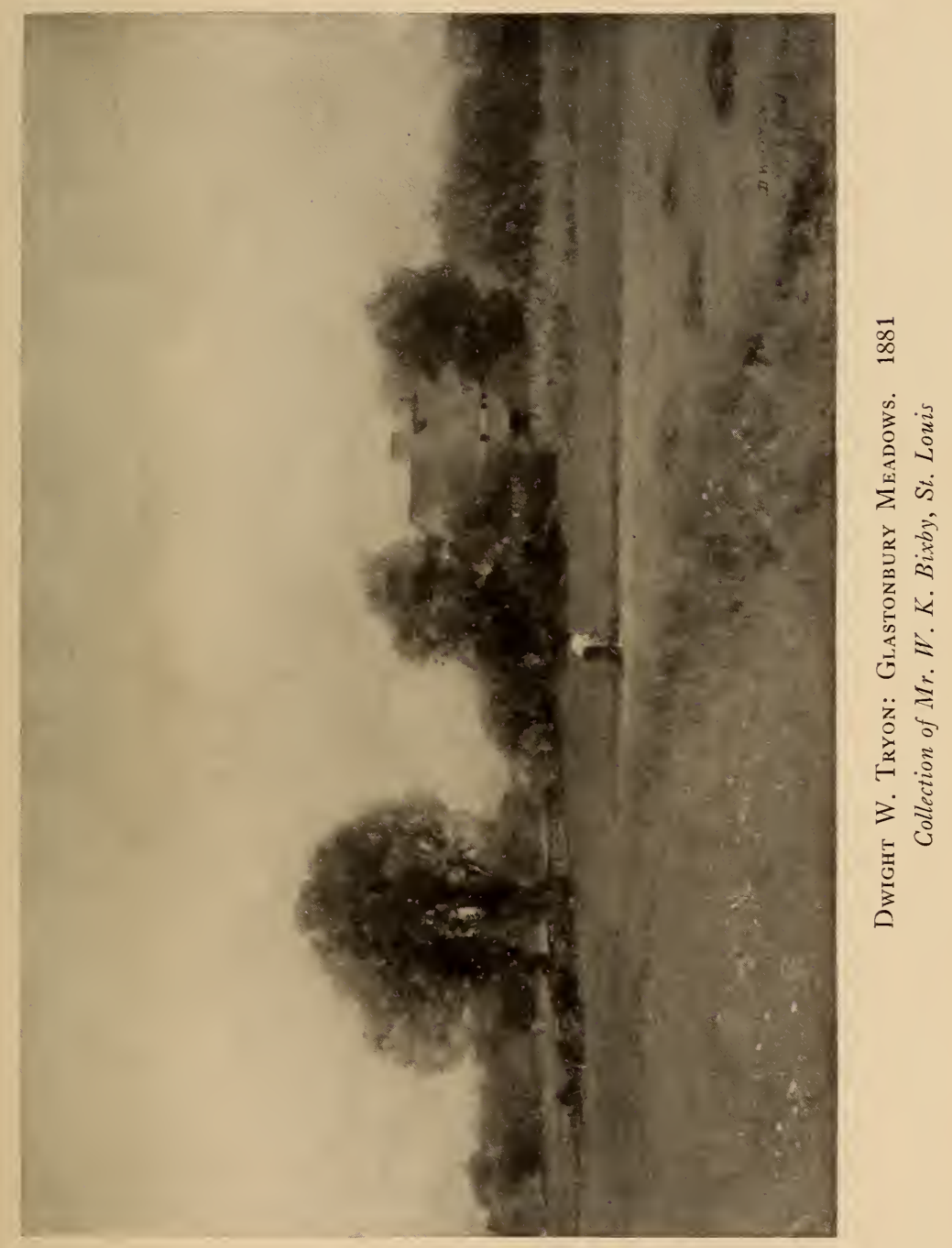





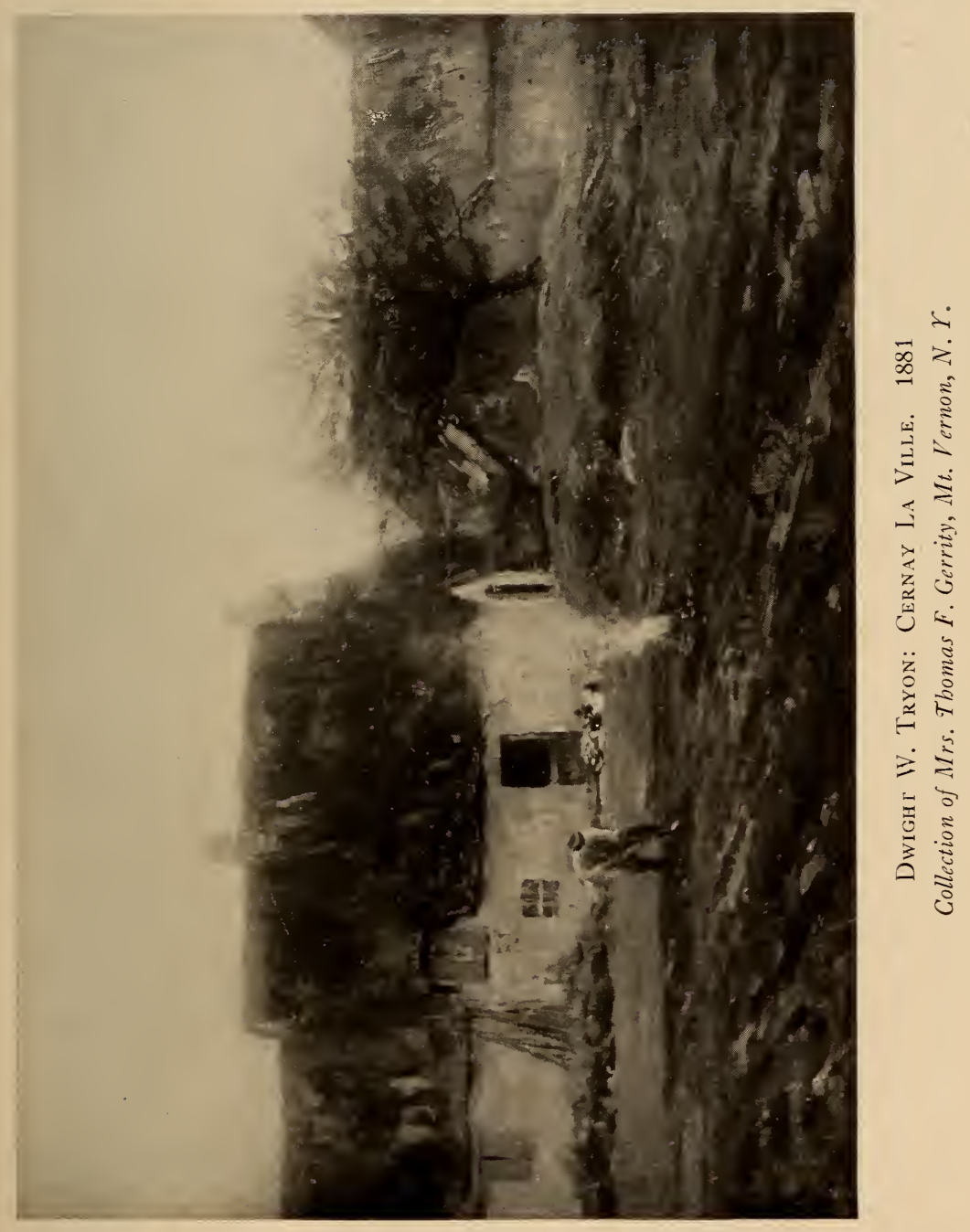



poetry of earth is evident in his pictures, but not any great portion of it, just a small measure of the minor poetry - a thin strain but no less sweet, whether it throb with the ecstasy of the spring, sparkle with the starlight of a summer's night, or shimmer with the silvery mists of morn. His eye is trained to envisioning the most transitory and the most elusive of atmospheric phenomena and this enables him to simulate them in the ethereal envelopment that serves a distinct purpose in accentuating the poignancy of his point of view. - With a few pictorial motifs he has contrived the evolution of an exquisite and alluring type of landscape, as accurate in its essential truth to nature as it is individual in its variation from other familiar types. If he is conscious of the limitations of a sort of fixed compositional form, which is characteristic, it is evident that he finds room therein for expressing very adequately whatever he has to say. This may be because he is contented never to try to say too much. His pictures are poetic but lyric, not epic in their intention.

His landscape has a firm foundation, for it is based upon a real knowledge of the topography of a section of the country with which he has been in close contact almost continuously. It is a real, not an imaginary landscape, though it may often seem. unreal in its unaccustomed beauty, as his effects approximate the unearthly splendor of those rare and 
exquisite moments he pictures. Singularly simple in its graphic portrayal of actual appearances, it is variously expressive of a considerable range of feeling which finds embodiment in the sensitive record of definite atmospheric conditions. As the weather affects us in real life, so it does in his art, where the mood of nature is the most important factor and informs the landscape with real meaning. In other words, it is the immaterial rather than the material evidence of nature that interests us in his landscape, just as in human nature it is character rather than personal appearance that interests us.

There is an earlier phase of Tryon's work in which there is more of the fact and less of the significance of nature. It ends practically as soon as he has mastered his forms and settled upon his composition. After that he is busy with light and shadow, values and quality, in which he finds a more efficient means for the expression of the emotional content of his theme. In the sense, however, that these earlier works are a more literal transcript of familiar rather than unfamiliar aspects of nature, more direct in their construction and less calculated in their elaboration, they correspond more closely to historic standards and satisfy more generally that large portion of the public which remains conservative in its appraisal of artistic merit. As few of us have yet outgrown entirely conservative tendencies, it follows 


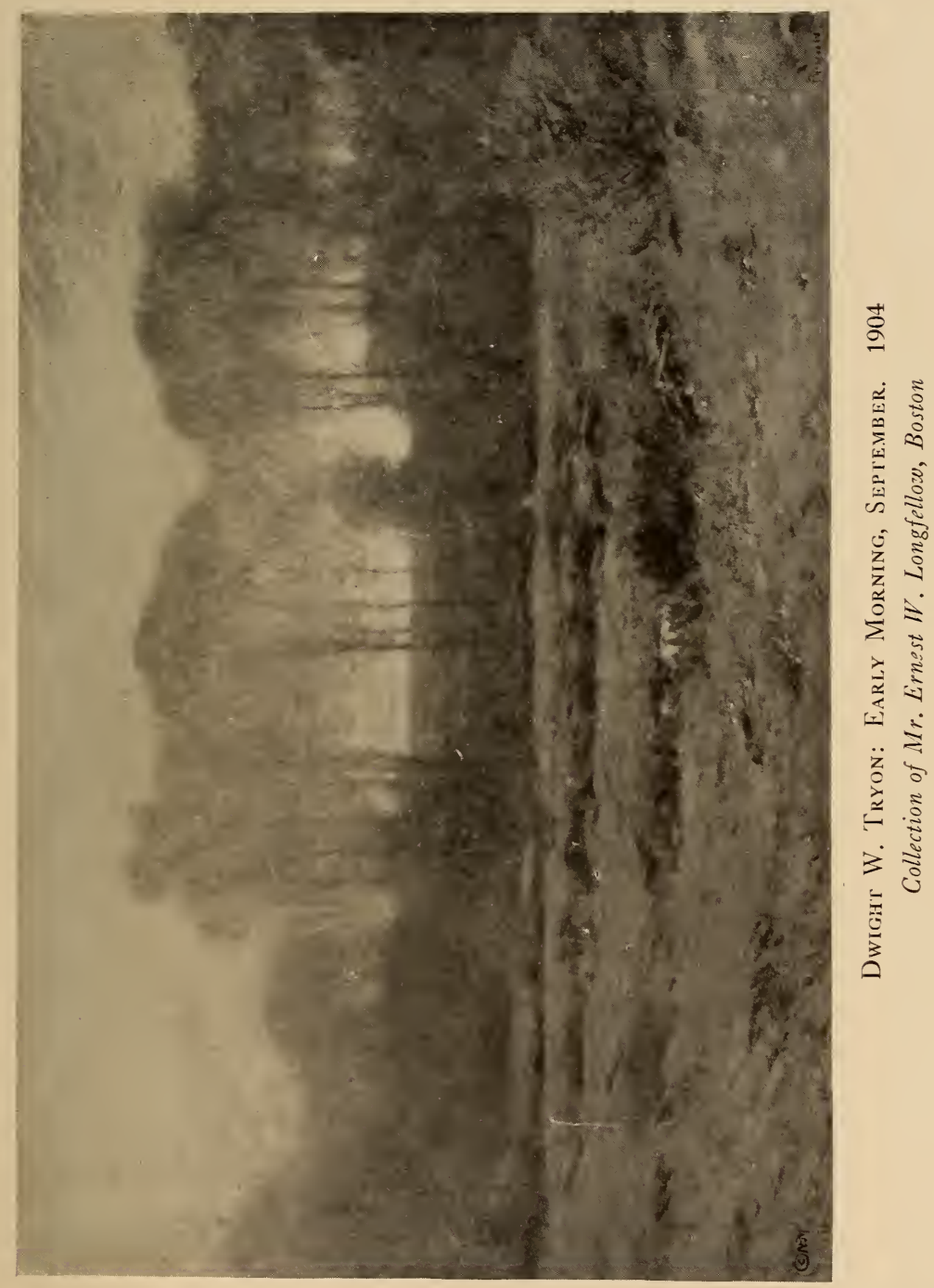



that practically all find in them much to admire. Only our recent and enthusiastic interest in, and knowledge of, the newer and finer developments of landscape painting enables us to appreciate the subtleties of his later work and to see in it a more notable achievement.

Several of the early pictures are of foreign subjects, the results of his student days in France. They are naturally not so convincing as the New England canvases in their characterization of locality. I have selected the Glastonbury Meadows of $\mathrm{I} 88 \mathrm{I}$ and the Cernay La Ville of the same year to illustrate the early phase of his art. The former is as literal in the exactitude with which it reproduces the topographical features of the country as it is lovely in its rendering of the pleasant quiet of a sunny summer's day. The scene is singularly satisfying in its familiarity and the fine simplicity of the composition emphasizes its peculiar charm. It is a masterpiece of what I should term the better sort of realism. The other picture is one of the finer of his French landscapes, full of an admirable sincerity. It has about it the air of an actual scene translated by the touch of art into a vision of measurable beauty:

The Early Morning - September of 1904 and the Twilight - November of I9I2 show the development of his art and are representative examples of the later period. In them one discerns an individual 
type of landscape and the evidences of a rare technic which he has all but perfected. It is, of course, not new, but it is very personal, and it helps him to re-create in delicate gradations of light and of shadow subtle atmospheric effects that are the visible signs of the moods of nature just as smiles and tears are the visible signs of human emotion. However lovely the face of nature, it is always her feelings that he is interested in interpreting, one might say, and it is this characteristic of his landscape that makes it interesting to us. One may estimate quite accurately the worth of any of his later works by the measure of one's realization of its emotional significance.

The objective world, its primitive and elemental grandeur, the naked truth of nature, as we see it in the works of other artists, concerns him not at all. His art is subjective and his interest is in the spiritual significance of the visible world as it is made intelligible in immaterial beauty. Whatever the material basis of his landscape, however true it may be in its portrayal of any actual area of the earth, the interest that absorbs the spectator's attention in it is almost invariably centred in the sky. His pictures are not so much remarkable as representations of the world in which we live as they are illuminating as expressions of something of the infinity of beauty that like a halo surrounds the earth. 


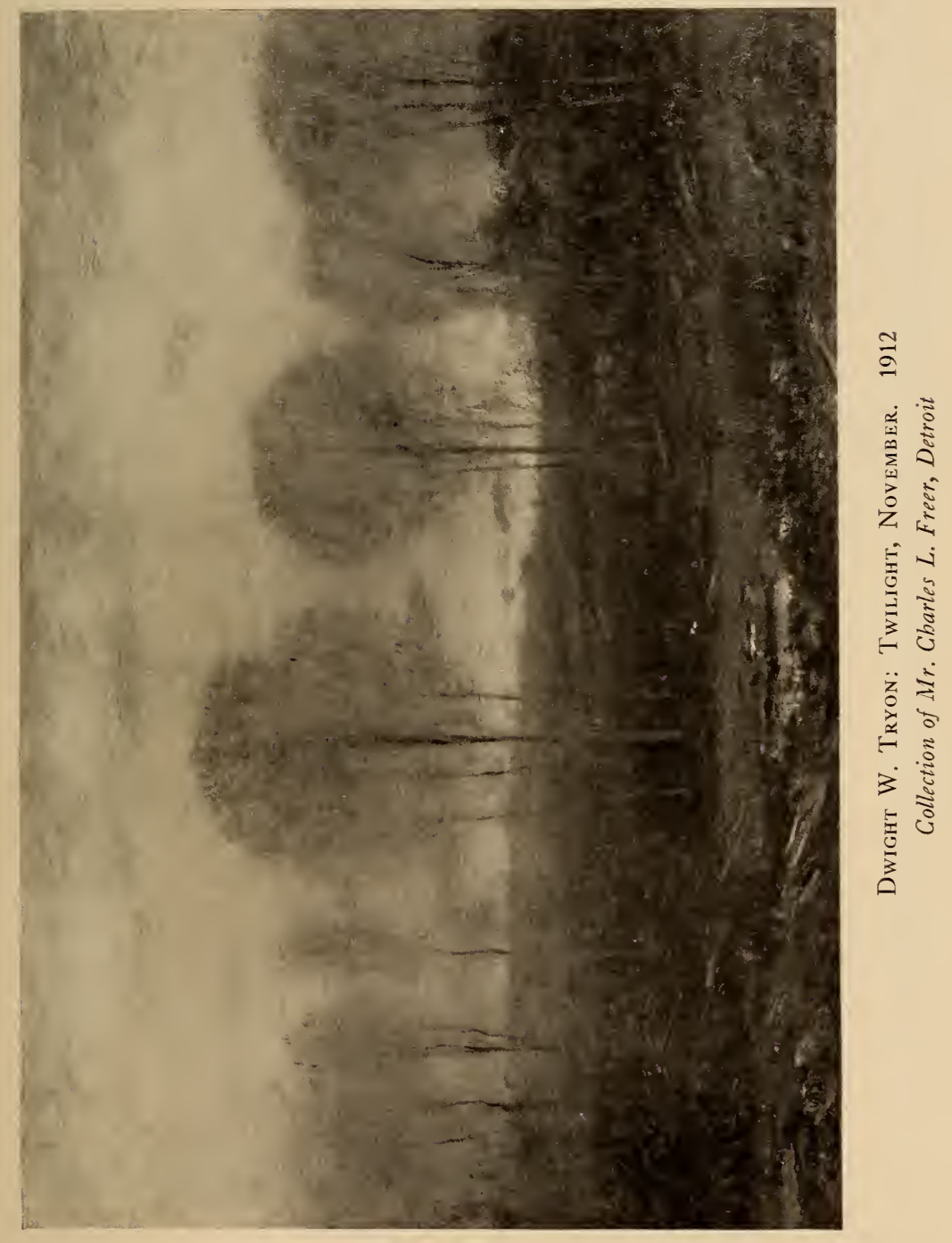



FOUR FIGURE PICTURES

BY GEORGE FULLER 



\section{FOUR FIGURE PICTURES}

BY GEORGE FULLER

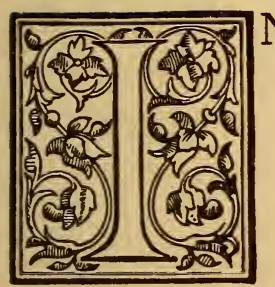

N I843 George Fuller wrote from his Deerfield farm to Henry Kirke Brown, then in Italy, "I have concluded to see nature for myself, through the eye of no one else." It may have been a decision forced upon him by circumstances that denied familiarity with the visions of other painters, but it was no less a wise one and resulted eventually in his creating a kind of picture distinctively different from those with which the public was already acquainted.

He may have underestimated the value of technic, for certainly time has made havoc with much that he did, but even when he wrote from Italy (whither he went in I860 to study the old masters) that it pleased him "to see how the old fellows went at their subject to tell their story, and how scumbling, light and dark shadows, took care of themselves," he added, "Yes, and drawing, too, not that these things are less important, but that something is more." The something to which he alluded was unquestionably the idea, the subject of the picture, which to him as to all of us constitutes its real sig- 
nificance and which, to borrow a phrase from the idiom of the theatre, an artist must "get over," or make the observer fully realize, if his work is to serve any useful purpose in the world. Whatever criticism may be properly applied to his method of painting, it cannot be denied that he did just that and with a manner comparable only to that of a great actor who impersonates characters upon the stage with such a semblance of life as to stir us to unaccustomed manifestations of feeling.

According to Fuller's way of thinking, "color in its highest sense is a delicate sense of gradation," and as Mr. Howells informs us in his brief sketch of the artist's life, "He preferred to remove the object of interest in his picture a degree into its atmosphere, believing that this gave a greater chance for expression," just as one might say that the stage provides an atmosphere for the actor in whatever rôle he may appear that enables him to realize more effectually its possibilities. This atmosphere in Fuller's canvases is adjusted always to that degree of definition he considered best suited to bring out the particular characteristics of the type pictured without discovering the obvious and inessential details of the mise en scène. It is because of this that the Nydia is so much more than an imaginary portrait of Bulwer's heroine. She is the personification of all the tragedy of the blind made doubly real 


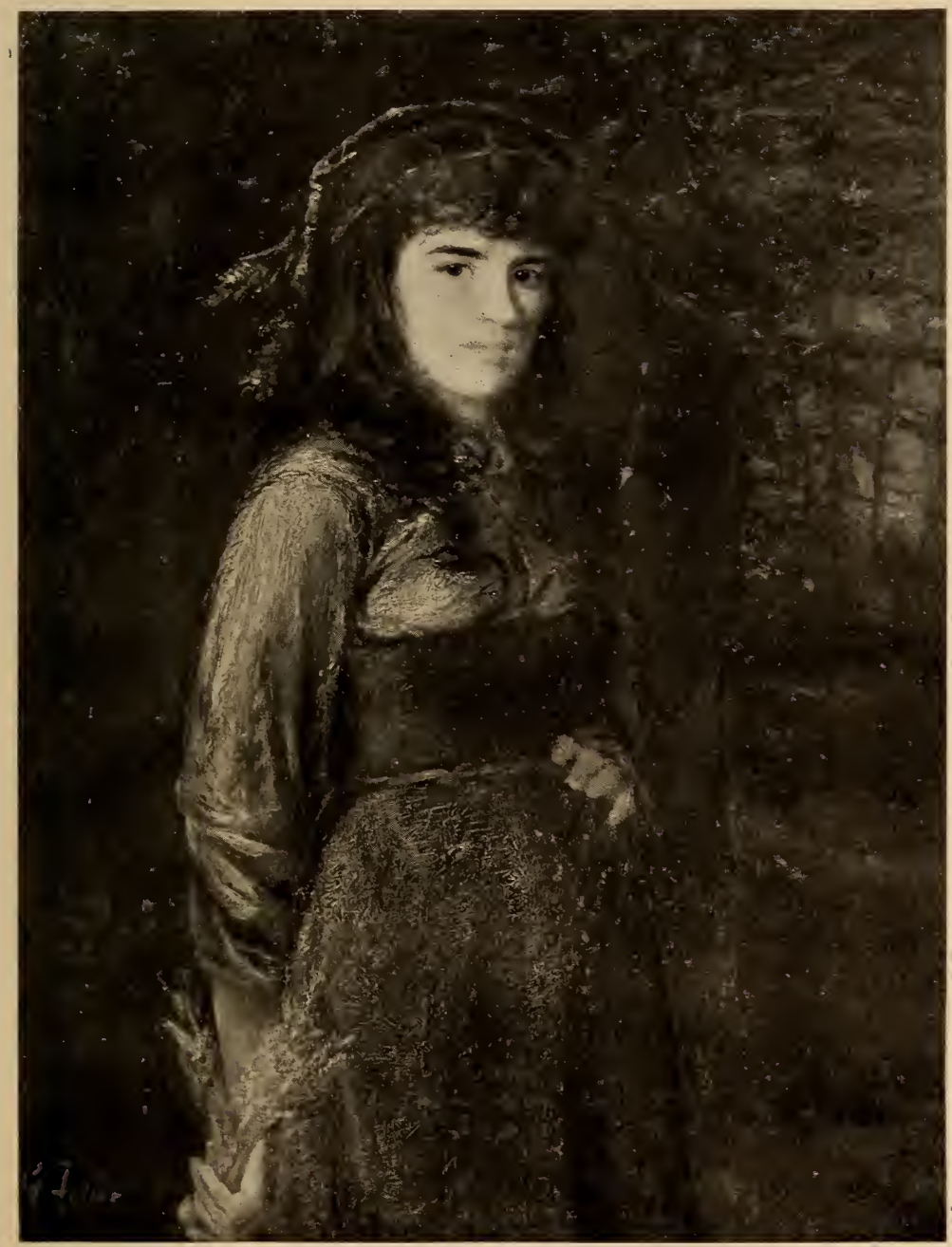

George Fuller: The Romany Girl

Collection of Mr. Henry Clay Frick, New York 



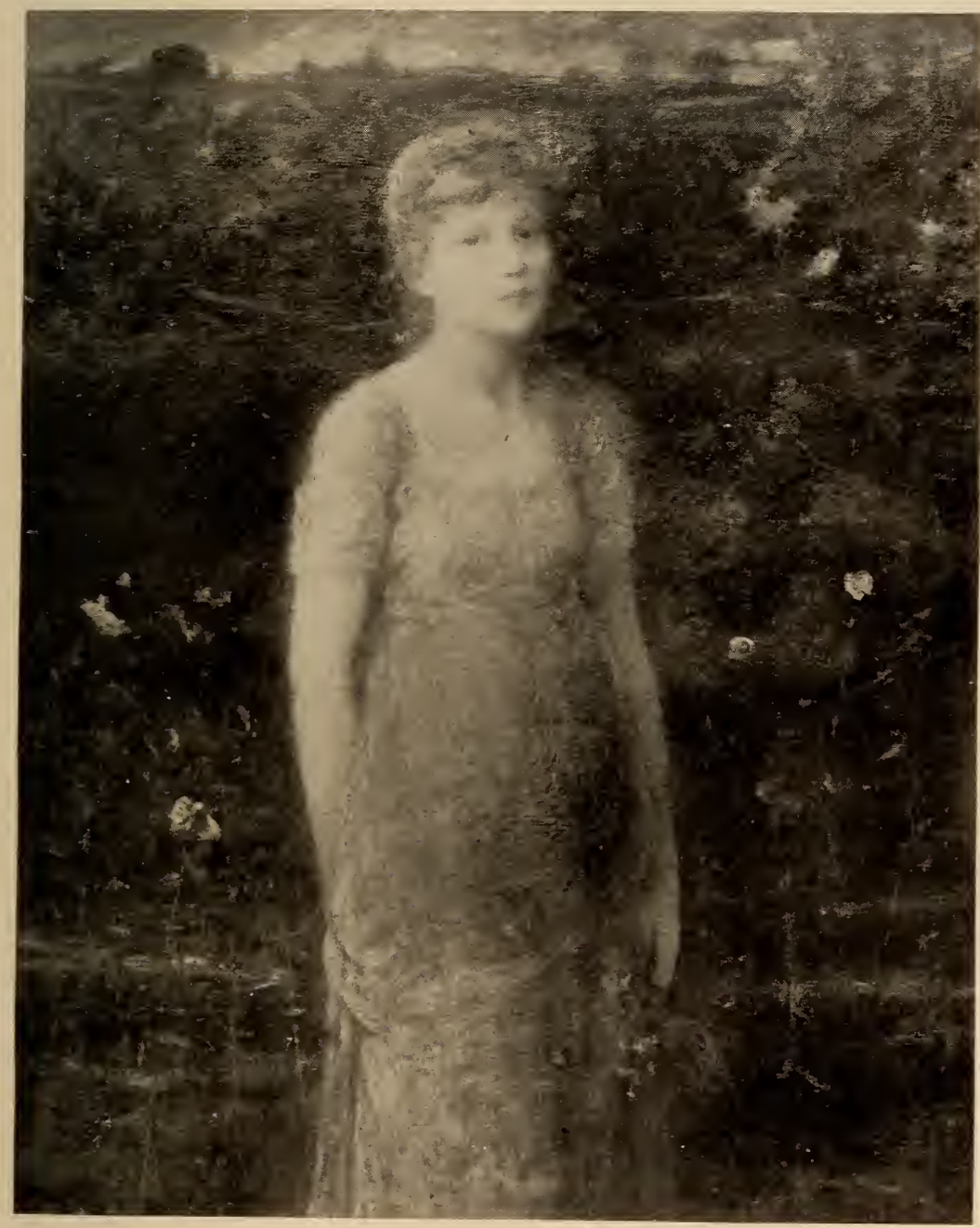

George Fuller: Winifred Dysart

Museum of Art, Worcester, Mass. 



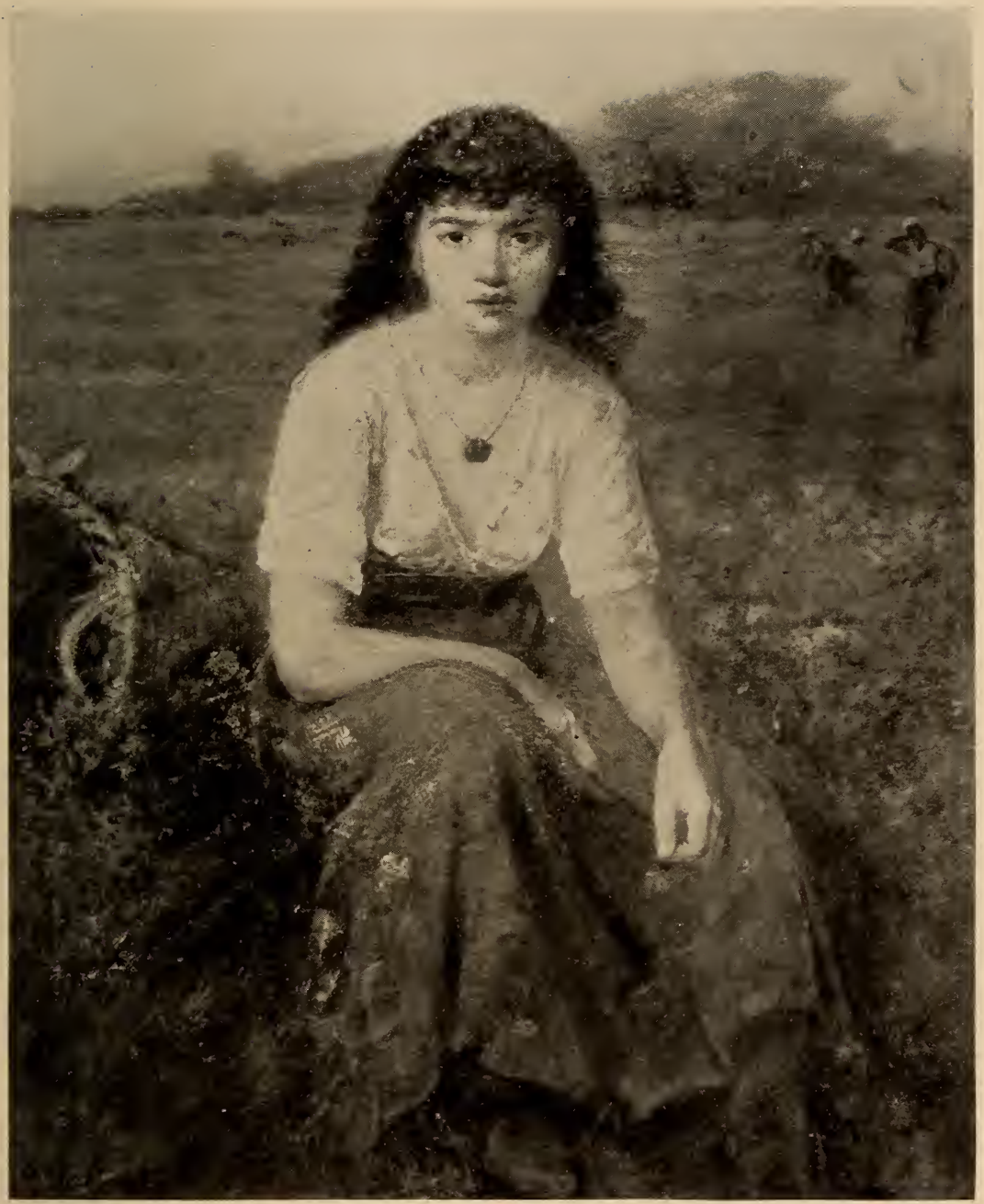

George Fuller: The Quadroon

The Hearn Collection, Metropolitan Museum of Art, New York 



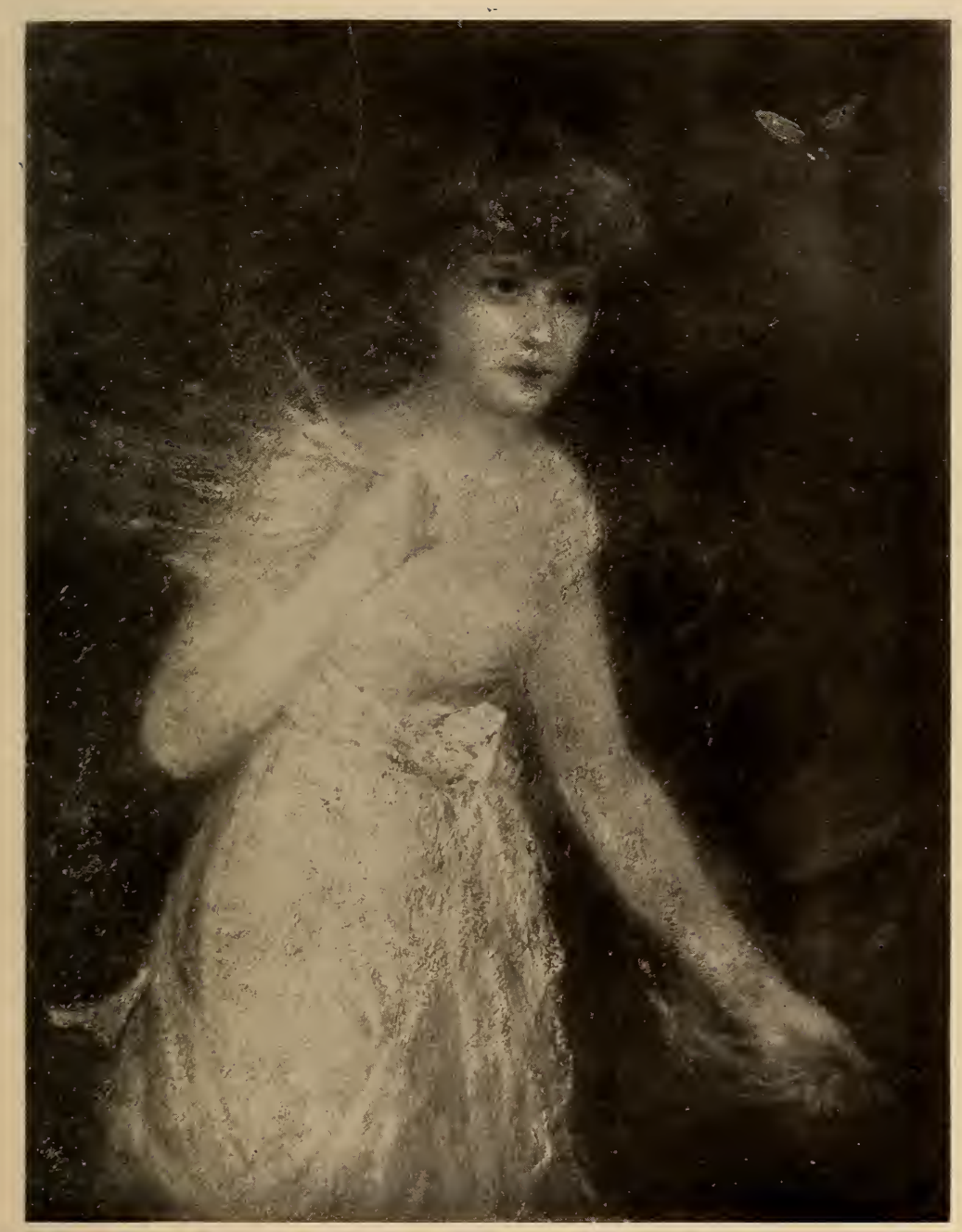

George Fuller: Psyche

The Art Institute, Cbicago 

and moving by her youth and beauty. There is nothing forced about the development of the meaning of such a calamity in the picture; rather is it apparently, though not actually, modified by his removal of the figure a degree into the atmosphere. It illustrates very forcibly, I think, the logic of his theory.

In The Romany Girl the characterization of the type is confined to a very sensitive interpretation of facial expression, and most of all one senses it in the gypsy light within her eyes. Of the vivid scarfs and kerchiefs we associate with the wandering tribes the artist has made no use and, except for the extraordinary head-dress and the sheaf of grain in her hand, there is nothing other than her look to indicate who or what she is. How fine was Fuller's perception of spiritual as distinguished from physical evidence of individuality is nowhere more apparent than in this canvas, where it is relied upon entirely to acquaint us with the character.

Of the Winifred Dysart I should say that it is patently more pleasing in color, more satisfactory in technic, but notwithstanding less significant and therefore less impressive than either of the paintings mentioned. It is, however, a sufficiently interesting picture to arrest one's attention anywhere and as likely as not to satisfy one quite as completely with its exquisite suggestion of the dreaming loveliness 
of maiden meditation. The figure is less mature even than the Nydia and a fraction more graceful, I should say; the pose simpler and finer, the drawing as good, and the idea perhaps only seemingly less perfectly embodied in the model because of the less dramatic quality of the conception. This girl is lyrical in her loveliness, the Nydia tragic in her trouble, and the Romany Girl romantic in her relation to life as we see from her glance.

The most touching and the most telling of Fuller's figure pictures, however, is, to my way of thinking, The Quadroon. Again it is a girl he chooses to interpret his idea, and, young as she is, he manages to invest her with the definite appearance of a comprehension of the sorrows of her inheritance, overwhelming if unconvincing to her troubled heart. In her he has contrived a graphic presentation of the bitter wrong mankind has worked upon man since time began, and has driven its meaning home by the look of weary despair that clouds her childish face. I know few modern pictures as perfect of the kind and they are numbered among the supreme masterpieces of the art of the nineteenth century: works like Whistler's portrait of his mother and Millet's Man with the Hoe. They are the present-day equivalents of such things as Caravaggio's Homer and Rembrandt's Saul listening to David playing the Harp. A certain indescribable but no less unmis- 
takable and miraculous similitude of life differentiates them from other canvases of their kind.

Every one of these great works of Fuller's which I have described was painted long after he had left the Deerfield farm where somehow he had found leisure to invent for himself a style that was eminently his own. The Romany Girl, which was the first in order of their inception, was begun in 1877 ; The Quadroon is of 1880 ; the Winifred Dysart followed in $188 \mathrm{I}^{\circ}$ and the Nydia in $\mathrm{I} 882$. He also produced immediately thereafter five other figure subjects similar in kind but not quite so fine, the Psyche, the Lorette and the Priscilla all in 1882 , the Arethusa in '83, and the Fidalma in '84. With these dates to go by it is not difficult to determine his best period as beginning in $\mathbf{1 8 7 7}$, when he made the first study of The Romany Girl. Especially as we know that this date is also that of the finest of his groups, And She was a Witch, a painting now unfortunately in a half-ruined condition and in immediate need of restoration. During his last years his reaction to the vicarious experiences of the creator of the beautiful, whose material is the emotional content of life, was less sure in itself, and his power to insinuate in the figures he portrayed anything like the same amount of feeling that is sensed in the presence of these figures is increasingly patent. He was able to visualize his ideas and the figures were expressive, 
but they never move us quite as those do that were painted just previously.

Fuller once said to an artist friend, "It is often what you leave out that makes your picture." $\mathrm{He}$ customarily left out a great deal, but he also put a great deal in, and it was as much what he put into his pictures as what he left out that made them, if I am not mistaken. Into his figures he put reality and as much of individual emotion and of the intellectual attitude of specific types as one will find anywhere in the art of his day. A power possessed by some painters of almost every period, but by few of any time in such a high degree, it ranks him with the greatest of those who have essayed the portrayal of human character as it is affected by the dominant influences of life. 
EARLY OIL PAINTINGS BY WINSLOW HOMER 




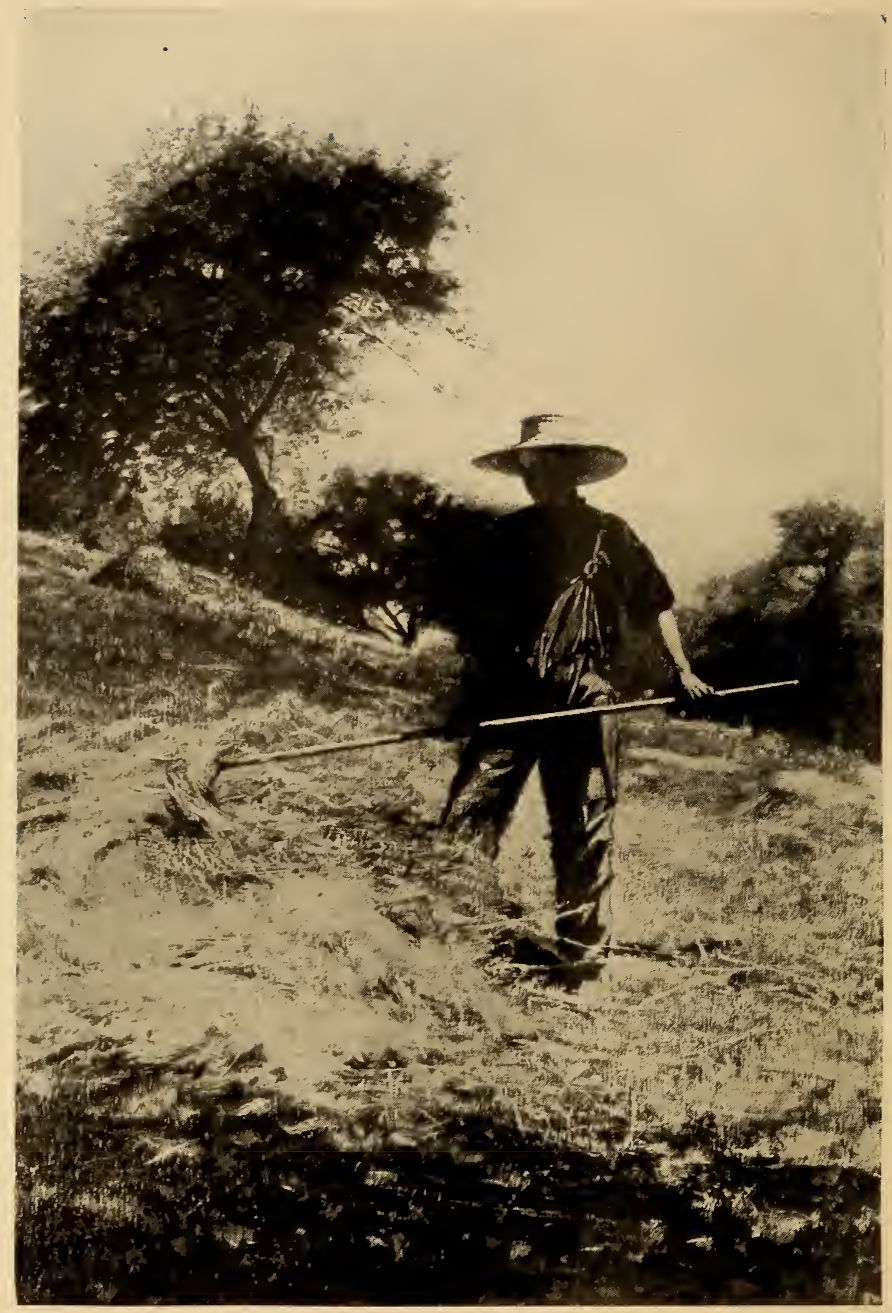

Winslow Homer: Haymaking

Collection of Mr. Frederic Faircbild Sherman, New York 


\section{EARLY OIL PAINTINGS BY WINSLOW HOMER}

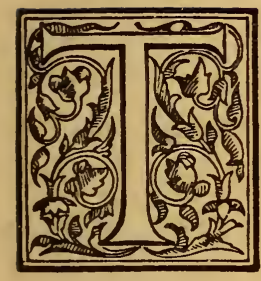

HOMAS BAILEY ALDRICH in I866 wrote of Winslow Homer's early studio in the old University building in New York, that "it is remarkable for nothing but its contracted dimensions; it seems altogether too small for a man to have a large idea in." As a matter of fact, most of Homer's ideas then, as later, came to him elsewhere; in soldier camps, at Houghton farm, in the North Woods, Bermuda or Maine. Eventually, however, the cramped life of the city, encompassed by walled streets and harassed by the unnatural noises of endless traffic, drove him to the distant coast of Maine, where he found a congenial home and his greatest inspiration in a supreme interpretation of the grandeur of the sea.

His reputation as a marine painter has been sufficiently established by the able exposition of other critics and needs no further emphasis, but I feel that there is something more of merit to be found in his early oil paintings than others have recognized. Admitting their technical deficiencies, which indeed he really never overcame, the charm of his farmyard 
and school-house pictures and the realism of his Civil War subjects are sufficiently compelling to permit one the belief that they have been somewhat neglected or certainly overlooked for the more pretentious marines which he produced in later years. It would be surprising indeed if an artist who was capable as a boy of eleven of producing such a masterly little drawing as that of the boys playing Beetle and Wedge should not achieve something of distinction in his early oil paintings of ten or fifteen years later. That none of Homer's canvases of this period are numbered among those which justify the preëminence of his position as an American painter is due more, perhaps, to the insistent dramatic quality of his later product than to any degree of artistic superiority in it sufficient to account for the prevailing neglect of the very notable compositions of his youth.

If he eventually concluded that the native farmhand was an inartistic subject, it was not before he had painted one or two pictures of him that are fine enough in themselves to hold their own, in every sense save that of mere size, with some of the more pretentious of his later works. I myself find the figures in his early paintings not merely more convincing in construction but more satisfying in their individuality. They may not be so heroic in form, but neither are they so wooden in structure as those that 


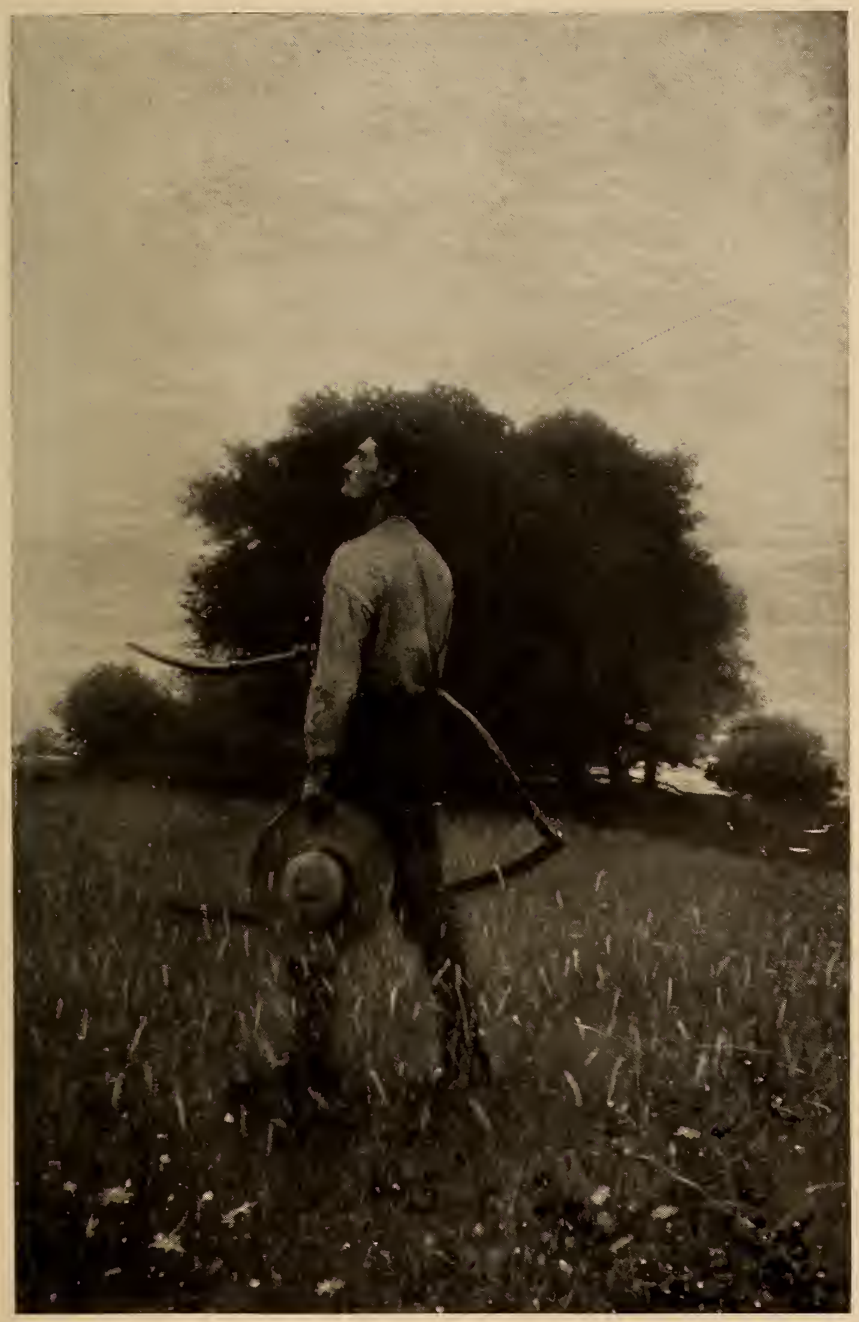

Winslow Homer: The Song of the Lark

The Hillyer Art Gallery, Smitb College, Nortbampton, Mass. 



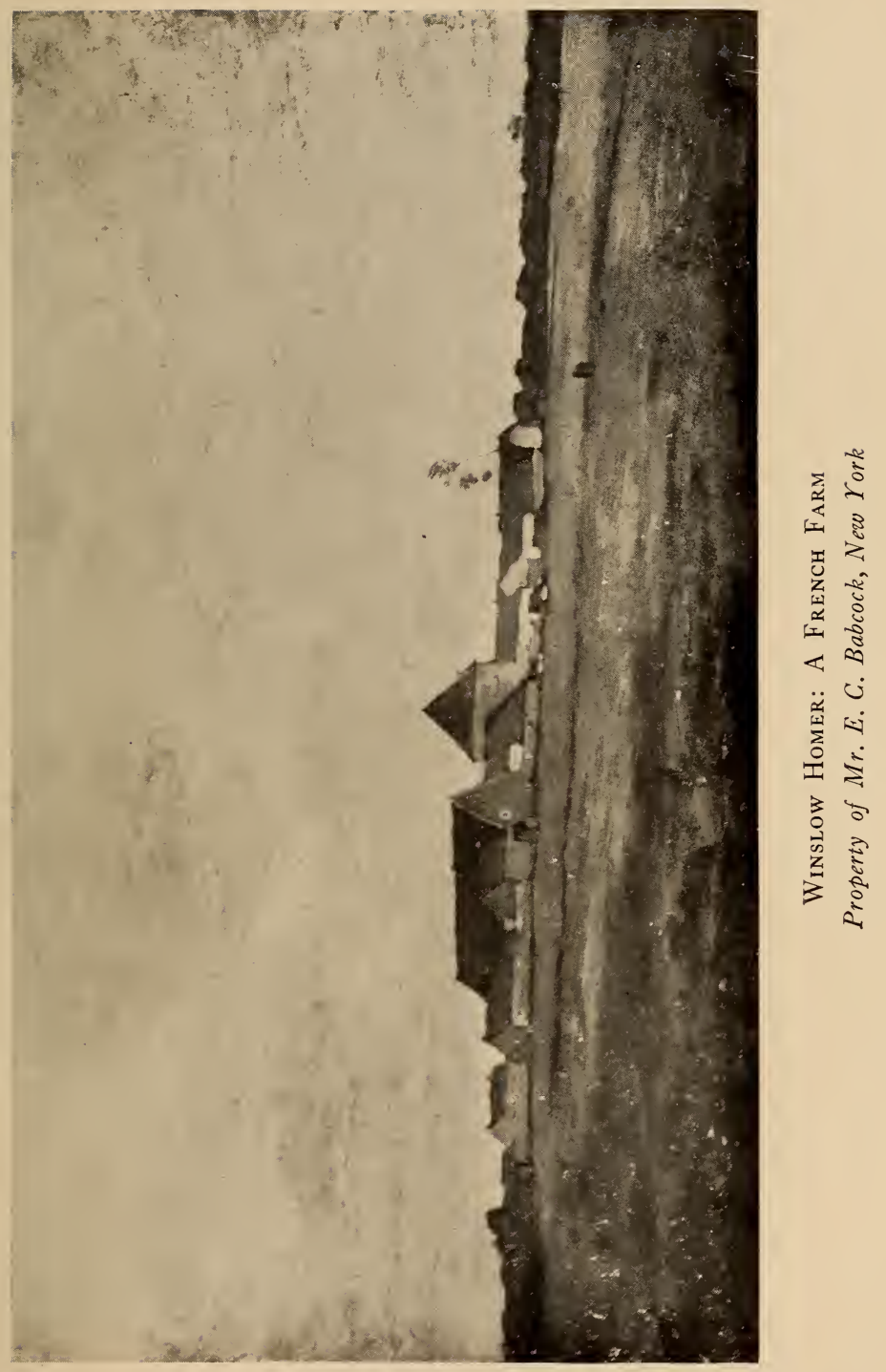



follow in his great marines. They have generally more reality in their obvious relation to their surroundings than the figures he uses to illustrate his stories of the sea. Probably the very fact that at first he aimed at nothing more than a truthful rendering of what he found interesting in life, instead of endeavoring to produce instantaneous records of its dramatic moments, is sufficient to account for the sense of reality I find in these earlier and miss in his later productions. Circumstance effectually precluded the possibility of his ever posing his models so as actually to paint from observation such pictures as The Life Line and The Undertow, and he had no sufficient knowledge of the figure to enable him to visualize, so as to paint from mental projections, the actual appearance of such scenes. Homer himself said that when he had selected a subject he painted it exactly as it appeared, and the sense in which this may have been true is indicated very clearly, I think, by the measure in which he failed in some of his later works to picture the figure with any sort of convincing approximation to that realism in which it generally appears in his earlier canvases.

Certainly the fact that a picture tells a story in no way prevents its being perhaps a great work of art, and in an exact ratio to the importance of the story a picture tells it may or may not be a masterpiece as an artist succeeds or fails in his presentation 
of whatever the subject may be. The common criticism of Homer is that he is an illustrator, not an artist; it is based upon an incomplete knowledge of his work and practically ignores the best of it those great marines that tell no stories and that have no meanings other than those that are inseparably associated with our thought of the sea, its power and its immensity. As a matter of fact, he was an illustrator and a very able one, and furthermore he was a great artist; he became a great artist whenever he gave up painting stories of the sea to paint the sea itself, as will be evident enough, I believe, to any one who contemplates such canvases as the Northeaster, and the Early Morning after a Storm at Sea.

It is worth while to remark that, precisely because Homer painted a subject exactly as it appeared, his pictures of the sea are the greatest of our time, for they are above all else masterpieces of realism. His early pictures also are eminently realistic and exact in their interpretation of everyday life, and very often as void of any literary meaning as the finest of his later works. They have always a human interest, however, associated with our knowledge of life, which suffices to arrest and hold the attention, and oftener than not they are really inviting in their coloring. The Haymaking, 1864, and Song of the Lark, 1876 (an idea which he used again, many years afterward, in the large canvas at Milwaukee), are 
excellent examples of the finer sort of realism one finds in his farmyard pictures. Here all is simplicity and the figure has all the accustomed value of its actual importance in the scene - no more, no less. The Musical Amateurs, formerly in the collection of Mr. John H. Converse and now owned by Mr. De Vine, possesses somewhat of the Whistlerian quality that Kenyon Cox has remarked in another early Homer, the New England Country School. Indeed, a sketch for the figure of the 'Cellist which I recently chanced upon reminded one very forcibly of another sketch of a 'Cellist, from the brush of Whistler himself, formerly in the late William M. Chase's collection and now in that of Mr. Frank Vanderlip. The Musical Amateurs is dated ' 67 and is not uninteresting in color. The sincerity of the study of the two musicians is sufficient to convey a definite idea of their personalities to anyone interested enough in such a subject to examine the canvas with the attention it deserves. And such an examination will discover in it also a fine tonality and a charming breadth of handling that was not at all common to the genre painting of the day in this country.

In these pictures of Homer's the pose, whatever it is, is natural, not theatrical in the sense that many of the figures in later canvases are obviously arranged in difficult tableaux to illustrate unusual stories: 
In doing just that sort of thing he oftener than not sacrificed too much of the realism, the truth, of life, to be very convincing, and to some of us, at least, a few of his greatest canvases can therefore never be anything other than noble failures.

In a picture like The Bright Side, I865, or The Visit of the Mistress, 1876, at the National Gallery, Washington, there is no attempt to tell any story. But the happy abandon of the negro teamsters in the former is as infectious as the quiet contentment of the latter is satisfying to the observer. The individualities of the people pictured are preserved in such a way as to convey to one an exact sense of their feelings, and it is because of this that the pictures appeal to us. They are notable examples of his ability to reproduce the sentiment as well as the appearance of a scene, and in their realism they compare with the best of his work in which the figure appears at all.

Of landscape Winslow Homer painted very little. The two examples that I reproduce, one comparatively early and the other quite late, are therefore of all the more interest, simply as illustrating a very uncommon and little known departure from his customary and familiar habit. The earlier picture is a result of his trip to France, and though appreciably tighter in treatment than the Prout's Neck sketch, it has all of the out-of-door feeling that so 


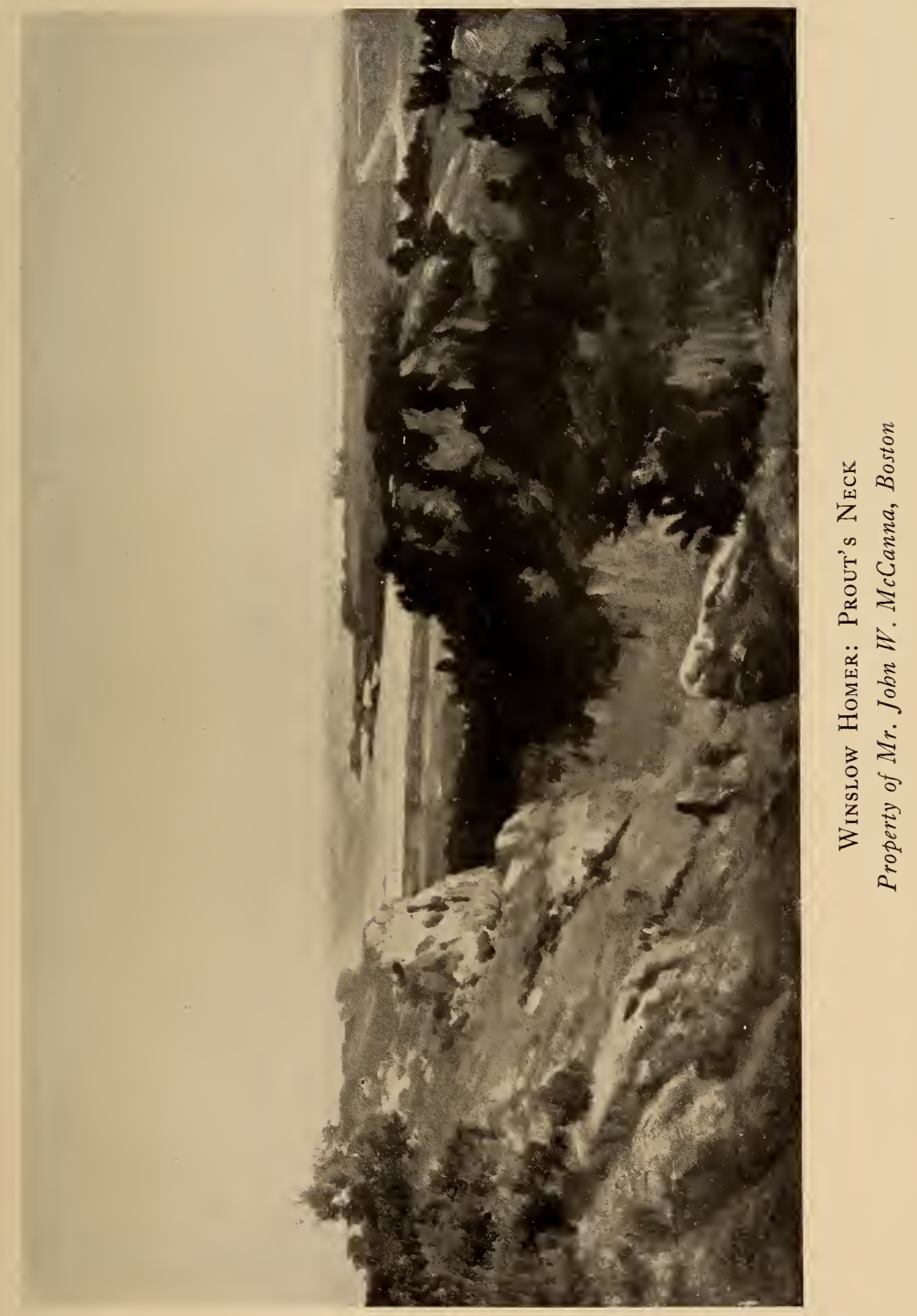



sensibly constitutes the persuasive charm of the later canvas. It is also entirely as enjoyable in color, and from it one gets definitely the feeling of locality which is a quality that differentiates honest from inferior landscape painting. The Prout's Neck is a study so marked with the conscious realization of actual appearances and an adequate rendering of their artistic interest as to persuade one that Homer might well have evolved from such an auspicious experiment a landscape as vital as the most impressive of his marines. It is instinct with the evidence of an intimate understanding of significant form, finished with a rare economy of effort in the matter of mere painting, and not only satisfies the most exacting expectations of the realist, but measurably fulfils the higher aim of pictorial art in its suggestive indication of abstract beauty. 

FIGURE PICTURES BY WYATT EATON 



\section{FIGURE PICTURES}

\section{BY WYATT EATON}

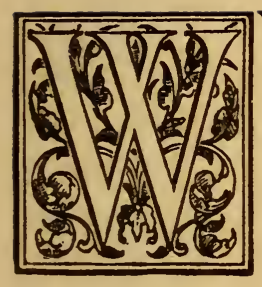

YATT EATON, whose parents were of New England stock, was born May 6, I849, at Philipsburg, on Missiquoi Bay, a tributary of Lake Champlain. As early as his eighteenth year he had determined upon his career, and going to New York began the study of art at the National Academy of Design under Samuel Colman, Daniel Huntington and others, working at the same time in the studio of Joseph Orion Eaton, from whom he also received instruction. Five years later, in 1872 , he went abroad and after a short stay in London, where he met and received some valuable suggestions from Whistler, he proceeded to Paris and entered the atelier of Gérôme at the Beaux-Arts. The next four years he divided between Paris and Barbizon, and during this interval was fortunate enough to become a sort of protégé of Millet's, who both criticized his work and favored him with good advice. Millet's influence, of course, is evident in much of Eaton's painting of this period, but he was neither a copyist nor a servile imitator, and very soon thereafter had developed a very char- 
acteristic as well as a very distinguished style of his own. Shortly after his return to this country he joined with Walter Shirlaw, Augustus St. Gaudens and others in the formation, in 1877 , of the Society of American Artists, of which he was the first Secretary.

He was singularly gifted, not alone as a painter but as a critic and a writer. His "Notes on the Early Italian Masters," "Reminiscences of Millet," and "Recollections of American Poets" are extremely interesting and suggestive reading. He was also as much of a master with pencil as with brush. His drawings, of which a considerable number have been preserved, are accurate and illuminating in their exposition of the persuasive beauty of the human form, very sensitive in touch and very alluring in line. He made portrait drawings from life of Longfellow, Whittier, Emerson, Holmes and Bryant, all of which were engraved by Timothy Cole and published in the Century Magazine. The portrait in oil of Bryant which now hangs in the Brooklyn Museum is perhaps the finest thing of the kind he produced, though he painted many portraits, not a few of which probably would be famous if known to the public. The Bryant has a solidity that is convincing and a frankness that is enticing. The brush is handled with great skill but with evident freedom, and a certain boldness that makes for bigness in the 


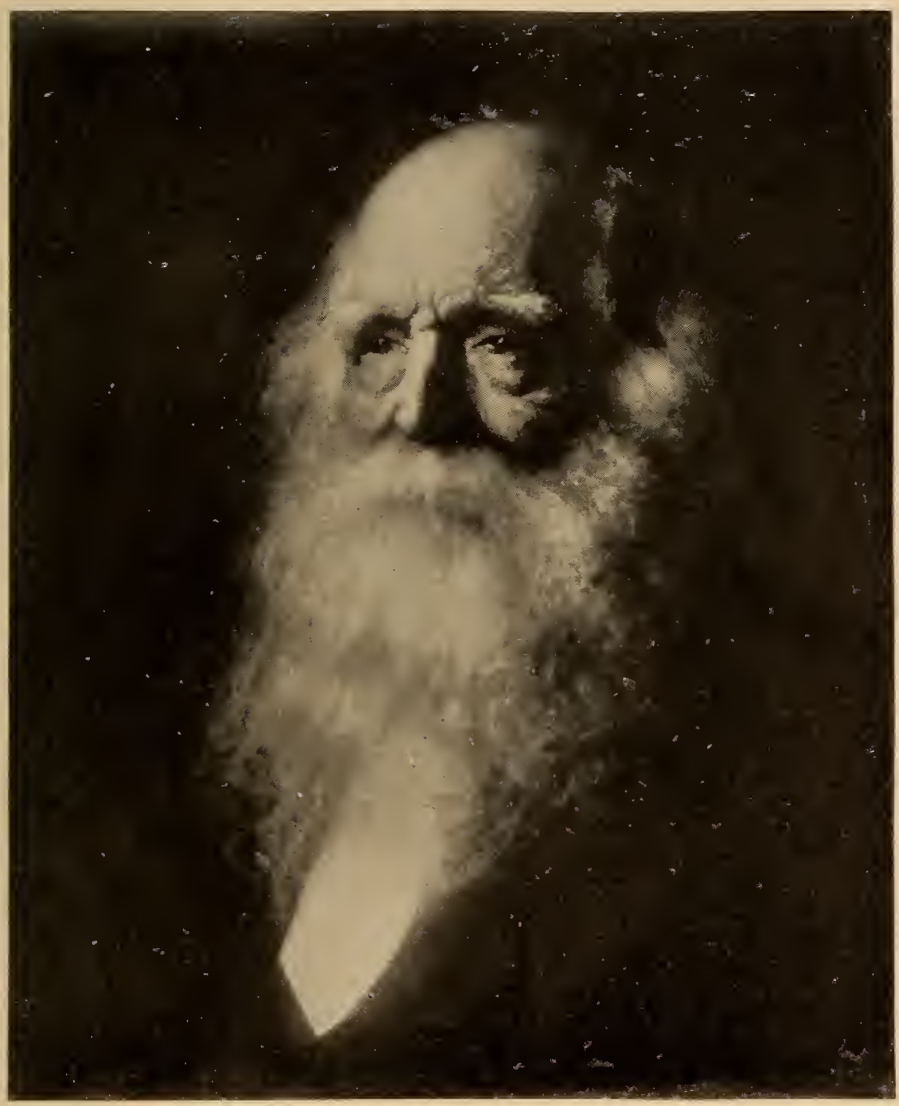

Wyatt Eaton: Portrait of William Cullen Bryant Museum of the Brooklyn Institute, Brooklyn, N. Y. 

best sense characterizes the technic of the painting. It is summary and yet restrained in handling, dignified and yet engaging as a portrait. Somehow he seems to me to have managed to incorporate in the likeness of the man the portrait of the poet, for the picture always suggests the author of the immortal things like "Thanatopsis" which Bryant wrote.

Mrs. Eaton in her brief sketch of her husband's life says that "one of his most cherished desires was to become a painter of the nude," and it may be added that his later years were pretty much devoted to the effort to realize this ambition. His works of the kind are few, but for purity and grace they are hardly to be excelled in American painting. The Ariadne in the Evans Collection at the National Gallery is to my mind one of our three greatest paintings of the nude. Felicitous and natural in pose, rich and harmonious in color, sweet and pure in feeling, it intrigues one with all sorts of happy suggestions of the idyllic charm, the tender and exquisite poetry of youth dreaming, as it were, in the safety of a paradise on earth. The Ariadne of John Vanderlyn is more famous because it is better known, but it is hardly so fine. Perhaps those who are partial to the painting of the period think it a finer work, but their reason for so doing can have nothing to do with any attribute of perfection save that which finds expression in the work of Bouguereau. The Vanderlyn-Bougue- 
reau type of nude has relatively little of the suggestion of life to recommend it, however perfect it may be in drawing and in modeling. In color it tends to sugariness and in line approaches the fixity of a "cast." The fleeting flushes of color that give charm to Eaton's nudes, the suppleness of line that imbues them with the semblance of life, the earlier artists neither understood nor attempted.

The remaining nude of Eaton's which I reproduce is, though unfinished, hardly less lovely than the Ariadne. To the painter and the serious student of painting it is peculiarly interesting, entirely because it is unfinished, as therefore it is possible to trace through various passages in it his manner of painting. Formerly the property of the late William M. Chase and entitled Lassitude, it is a fascinating study of a model resting against a greenish drapery in slumberous relaxation, the light falling full upon the figure and emphasizing the graceful physical beauty of the supple form and the evanescent pearl and ivory tones of the nude flesh. The workmanship is wonderful in its suggestion of the painter's understanding of the problem; everything is finished in its finality so far as he has gone with the canvas; and because one feels how surely it would have eventually realized all expectations if he had lived to complete it, it has somehow almost the distinction of a finished work. 


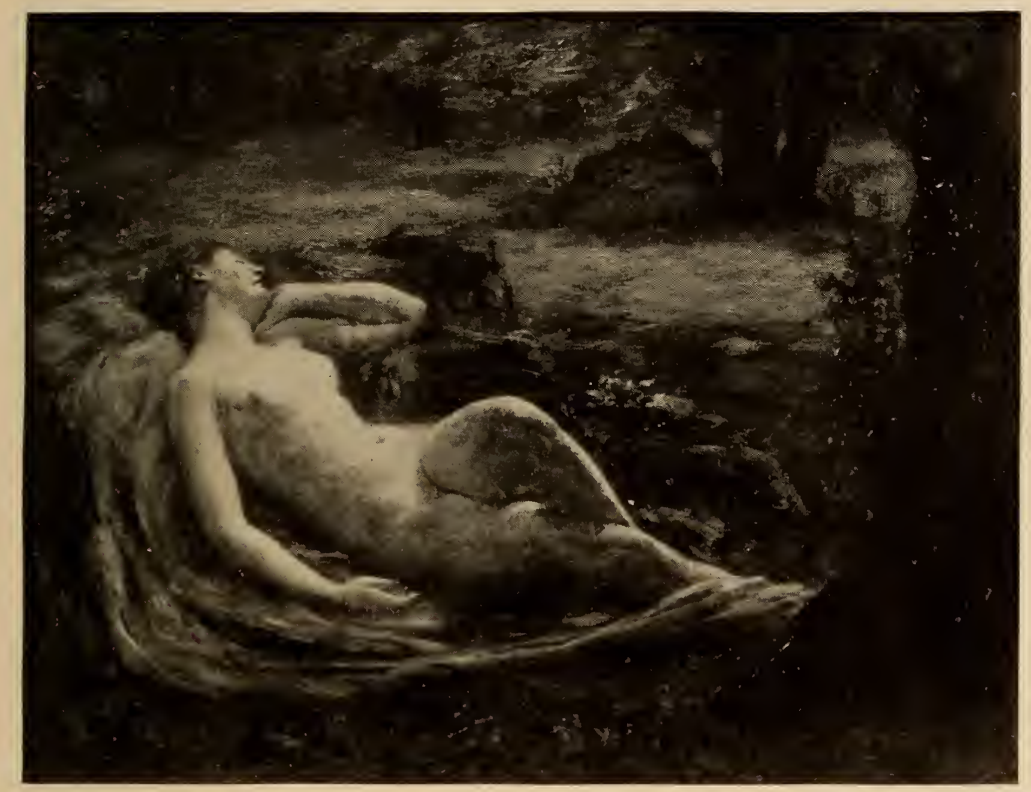

Wyatt Eaton: Ariadne

W. F. Evans Collection, National Gallery, Wasbington, D. C. 



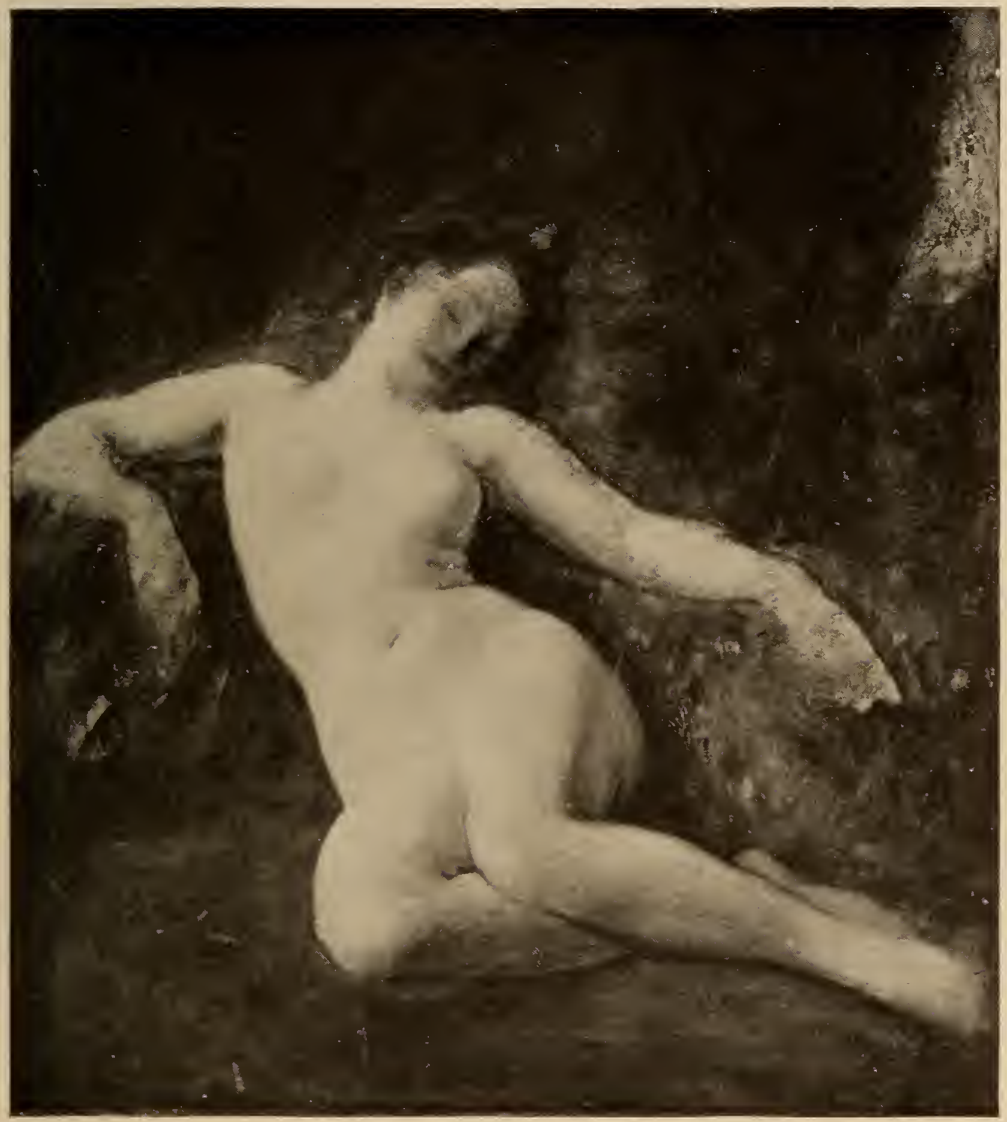

Wyatt Eaton: Lassitude

Collection of Mr. Frederic Fairchilt Sherman, New York 



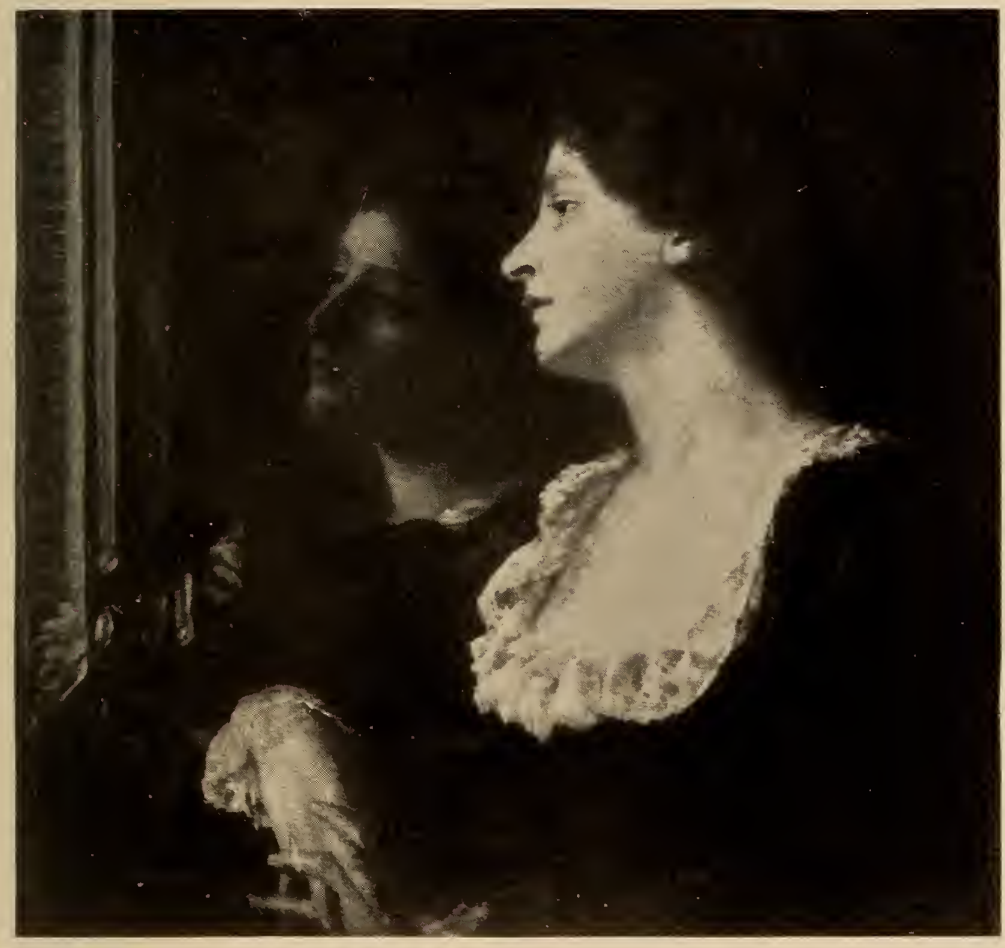

Wyatt Eaton: Reverie

Collection of Mr. Frederick B. Pratt, Brooklyn, N. Y. 

The Reverie is a picture of a more popular pattern, but a very unusual and expressive one. Its chief interest is as an interpretation of a particular mood, though the obvious elegance of the arrangement or design is too apparent not to occasion remark. The brushwork is very deft, the touch fluent and the color gracious and reserved, as befits the subject. No detail of dress or surroundings is sufficiently developed to divert one's attention, howsoever slightly or momentarily, from the supreme interest of the canvas, and yet the fabrics of the costume are painted with consummate skill and the reflection in the mirror is well-nigh a piece of pure perfection in pictorial art.

Wyatt Eaton's oil paintings are not common; only three that I know of are in public museums the Ariadne at Washington, the Harvesters at Rest at the Hillyer Art Gallery, Northampton, Mass., and the William Cullen Bryant in Brooklyn. Several others I am familiar with are in private collections, besides a number of portraits in Canadian homes. His work in oil is, I think, almost as lovely as it is rare, and any representative exhibition of it would, I feel confident, result in a belated realization of the genuineness of his genius and might rank him with the relatively few American masters.

One unconsciously recalls the old saying about "those whom the gods love dying young" when looking at the most beautiful of Wyatt Eaton's pic- 
tures, though, save in the sense that he did not live to be an old man, he was not really young when death overtook him. He died June 7, 1896, at Newport, R.I., in his forty-eighth year. His works, whether portrait, figure composition, nude or landscape, always have about them an air of classic simplicity. Tricks of technic, beauty that is only skin deep, either of the human countenance or of oil paint, design that is dominating if not dignified, he happily managed to do without. Nothing, I imagine, interested him so much as the effort to get at the truth, whether it had to do with a reflection in a mirror, a human likeness, some scene from nature or an undraped figure; and the more I study his product the more strongly I feel that truth is not only "stranger than fiction" but also more beautiful. $\mathrm{He}$ is a consummate craftsman who can dispense with most of the proverbial license that is allowed the artist and yet manage to produce a real work of art, and Wyatt Eaton succeeded at times in doing just that - primarily because it was rather truth of feeling than merely accuracy of representation that he aimed at in his canvases. 
ARTHUR B. DAVIES 



\section{ARTHUR B. DAVIES}

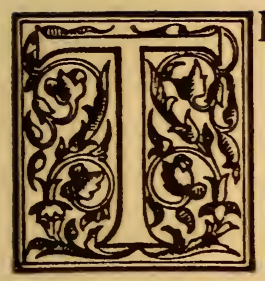

HE ingenuity of Mr. Davies' invention invests his painting with unusual interest. His landscape presents many original and engaging patterns in which the imagination threads secret pathways of delight, and his figure pieces delicately suggest in design ideas that are frequently as unsubstantial as dreams and as lovely. The eclecticism that is evident in his work in no wise interferes with the individual taste observable in its elaboration or the personal quality of its appeal. Many of his later canvases are attractive illustrations of moments of classic enchantment shepherds piping to their flocks upon the heights of Parnassus, nymphs dancing in the Vale of Tempe, or maybe a group of unicorns gravely regarding some unfamiliar vista of terrestrial grandeur. Keats' description of the relief upon the Grecian Urn is the immortalization of that significant beauty one glimpses in his paintings.

His earlier canvașes are generally richer in color than his later works and embody a more humble and more human and therefore more understandable presentation of various manifestations of life illumi- 
nated with a touch of recognizable realism. Their spontaneity is too obvious to allow of their escaping attention and their rare simplicity too intriguing to permit of their being neglected for the more calculated and hence more compelling effectiveness of his subsequent creations. In the Girl at the Fountain, which is no more than a mere sketch, and a very early production, one realizes definitely the sense of seeing a child actually engaged in the performance of a homely act. The intellectual enjoyment of the picture is established by the sincerity of the study. It is one of those infrequent examples of a perfectly adjusted sketch in which the reserve of drawing, design and technic results in a balance of exquisite artistic finish nicely calculated to just that suggestion of the poetry of life that colors a drab experience with the richness of romance.

The Violin Girl, framed as a water-color in a wide paper mat when recently shown, is an early picture very different in execution and effect. A composition as convincing in its indication of actuality as the earlier picture of the Girl at the Fountain, the figure is drawn with extreme care and finished with a degree of precision that is unique in his art. The rich tonality of its depths of sensuous and satisfying color achieves an effect possible only to the medium as it produces the emotional equivalent of music in similar harmonies of sensitive interpretation. The pose, 48 
restricted as it is by the action, is relieved of any semblance of the commonplace by a conscientious elimination of all superfluous triviality of detail, and the picture is made really memorable by a subtle rendering of facial expression through which a definite realization of the emotion is communicated to the spectator. The work has something of the simplicity of design and of the elegance and refinement of color that one associates with Florentine painting of the Renaissance, without any suggestion of it, however, in the more obvious and essential characteristics of technic or intention. Color more eloquent than that in this picture one seldom encounters.

Several of Mr. Davies' finer decorative panels with figures have something of the supreme refinement of the sculptured friezes of antiquity and as little relation to actual life. They are superlatively attractive representations of the immortal beauties of fable rather than of fact, and to admit that they continue to appeal to certain subconscious predilections for what one may term art for art's sake long after one's first enthusiasm over them has definitely passed, is to acknowledge an approximation to artistic perfection that becomes a patent and permanent interest upon fuller acquaintance.

The development of Mr. Davies' technic is apparent in a consistent effort to realize in his line with relatively flat color the utmost of pictorial represen- 
tation. It is a method as difficult as it is direct and provides for little more in the way of alteration or elaboration than water color. On the other hand, it presents possibilities of realizing beauties of the brush that are inevitably lost in the manipulation of mere paint. Working in this way is practically freehand drawing in thin color with the brush and one must needs be a consummate draughtsman to attempt it with any hope of success. In what he has now to show there is noticeable, at times, a fluffiness or woolliness of pigment that veils the very line through which he essays to establish the perfection and the permanence of a vision that informs his pictures with unique and individual charm.

A very expert and extremely facile craftsman, his latest works have more the appearance of elaborate exercises in drawing than of anything that can be reasonably described as authentic artistic creation. Without any sensible meaning and lacking sufficient vital significance to even suggest that which they lack, these pictures display, nevertheless, a degree of skill expended in fruitless experiments in the intricacies of linear design that might very possibly suffice to express living thoughts in some such way as to produce real masterpieces. One is constantly aware, in looking at them, of Mr. Davies' prodigious delight in the display of his facility, but in so much as one looks for anything more than fine drawing, 


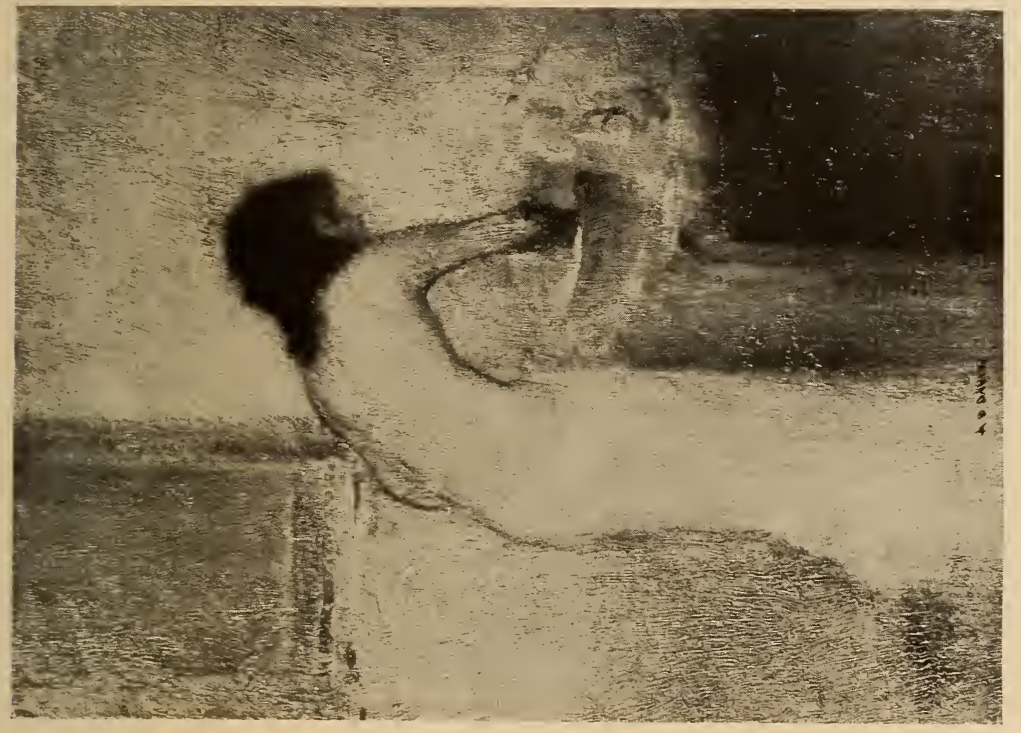

ż

II

녹

4

ڤั)

is

$\sum$

2

$\sim \stackrel{2}{5}$

ำ

Z

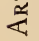

iิ

i.

i

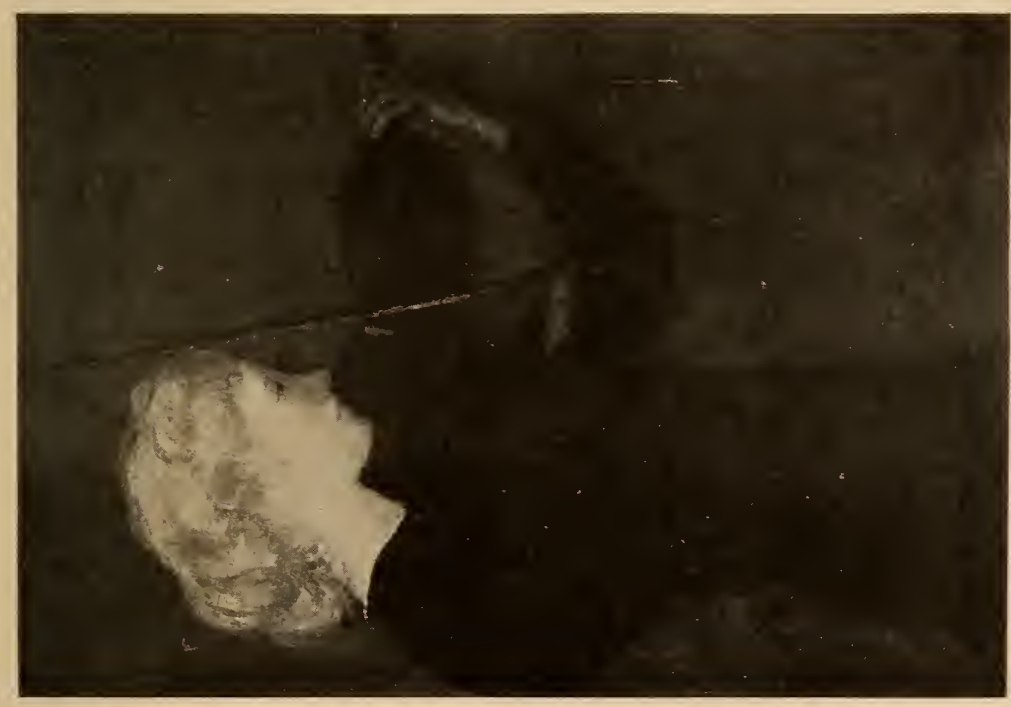

$n$ 



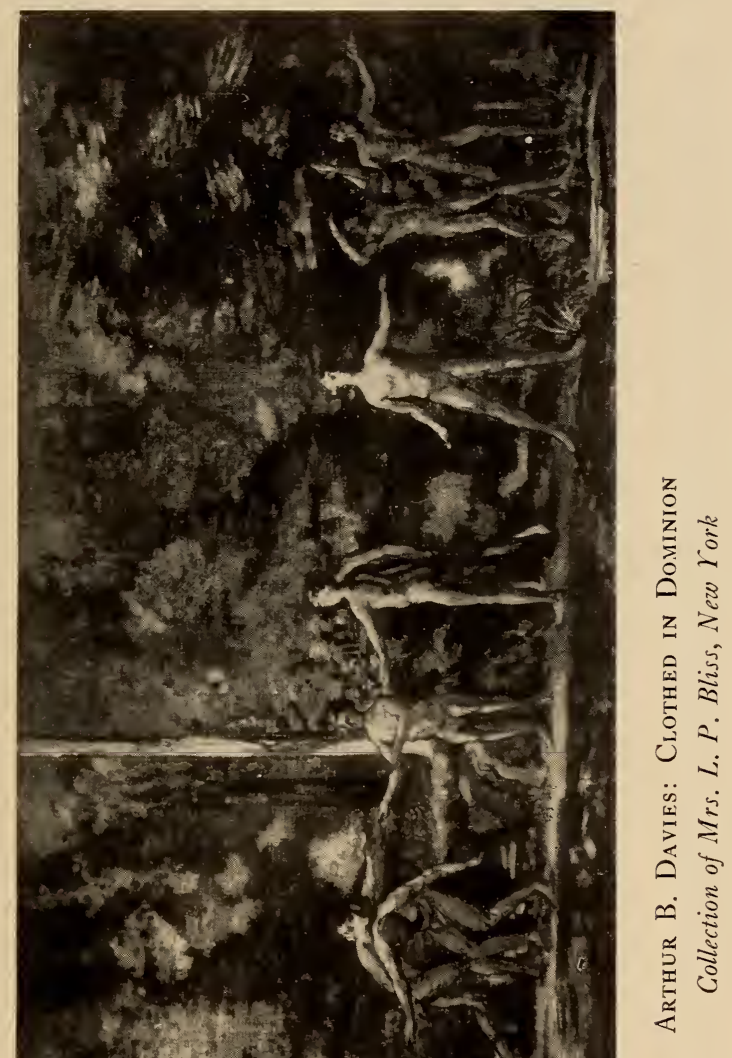



color or design in a picture they are consistently disappointing. If, indeed, these works have any meanings at all, they are entirely lost in a style of composition at once too involved for the human understanding and too evidently egotistic and personal to permit of any permanent intellectual enjoyment even if they were intelligible. To represent any number of exquisitely satisfying human figures so muddled together in elaborate denial of the most elementary requirements of grace, or so twisted and tortured in unnecessary and unnatural contortions as to recall nothing if not man's animal ancestry, is hardly evidence of an impulse likely to add anything of lasting importance to the art of today. I do not know of a single recognized masterpiece in pictorial art that does not either express an idea or convey a suggestion of something other than the mere ability of the artist. It is precisely these ideas and these suggestions that enliven with interest and inform with vitality those paintings of every school and of every master that really achieve greatness. 

EARLY GENRE PICTURES BY HARRY W. WATROUS 



\section{EARLY GENRE PICTURES BY HARRY W. WATROUS}

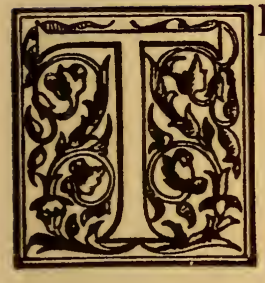

HERE are today practically no painters of the type of genre picture of cabinet size that Vibert, Meissonier, and Bargue made famous during the last century, though as late as the eighties there were still a number of younger men studying in Paris who painted such works. Harry Watrous, who is known today entirely as a painter of a very different kind of picture, was one of this little band. It is to these early canvases of his that I wish to call attention now both on account of their very obvious merits and because they constitute almost the only works (excepting some by Louis Moeller, Ignaz Gaugengigl, and Alfred Kappes) of American production belonging to an extremely interesting and beautiful though no longer popular type of picture.

The particular sort of painting we are considering is, of course, descended directly from such seventeenth-century masters as Metsu, Terborch, and Vermeer. The modern artists consciously endeavored to duplicate the same qualities that distinguish the pictures of these Dutch masters of the great 
period, while reproducing the life of their own time. The most obvious difference in manner is perhaps an increased definition of detail in the later work and a corresponding sacrifice of that fine simplicity that gives dignity to the most trifling subjects treated by the great Dutchmen. Surfaces the nineteenth-century artist painted perhaps as skilfully as they his velvets and furs, satins and still-life are well-nigh perfect, but the greater problems of lighting, which the Dutchmen definitely solved and in so doing made of their pictures real masterpieces, the nineteenth-century painter never satisfactorily solved at all.

The vogue of these little genre pictures is now so entirely a thing of the past that one perhaps overestimates somewhat their beauty and their charm. Attractive examples are sold at auction every year for modest prices and, as none are being produced today, one cannot but feel that their future is assured and that it will see them reëstablished in public favor and eagerly sought after by the connoisseur of the next generation.

The pictures of Mr. Watrous in this vein which I shall mention were all painted in the few years from $I 883$ to $I 888$, when he was a very young man, and show an astonishing ability in handling difficult technical problems with real success. It is not a simple matter to reproduce with oil paint the sheen 


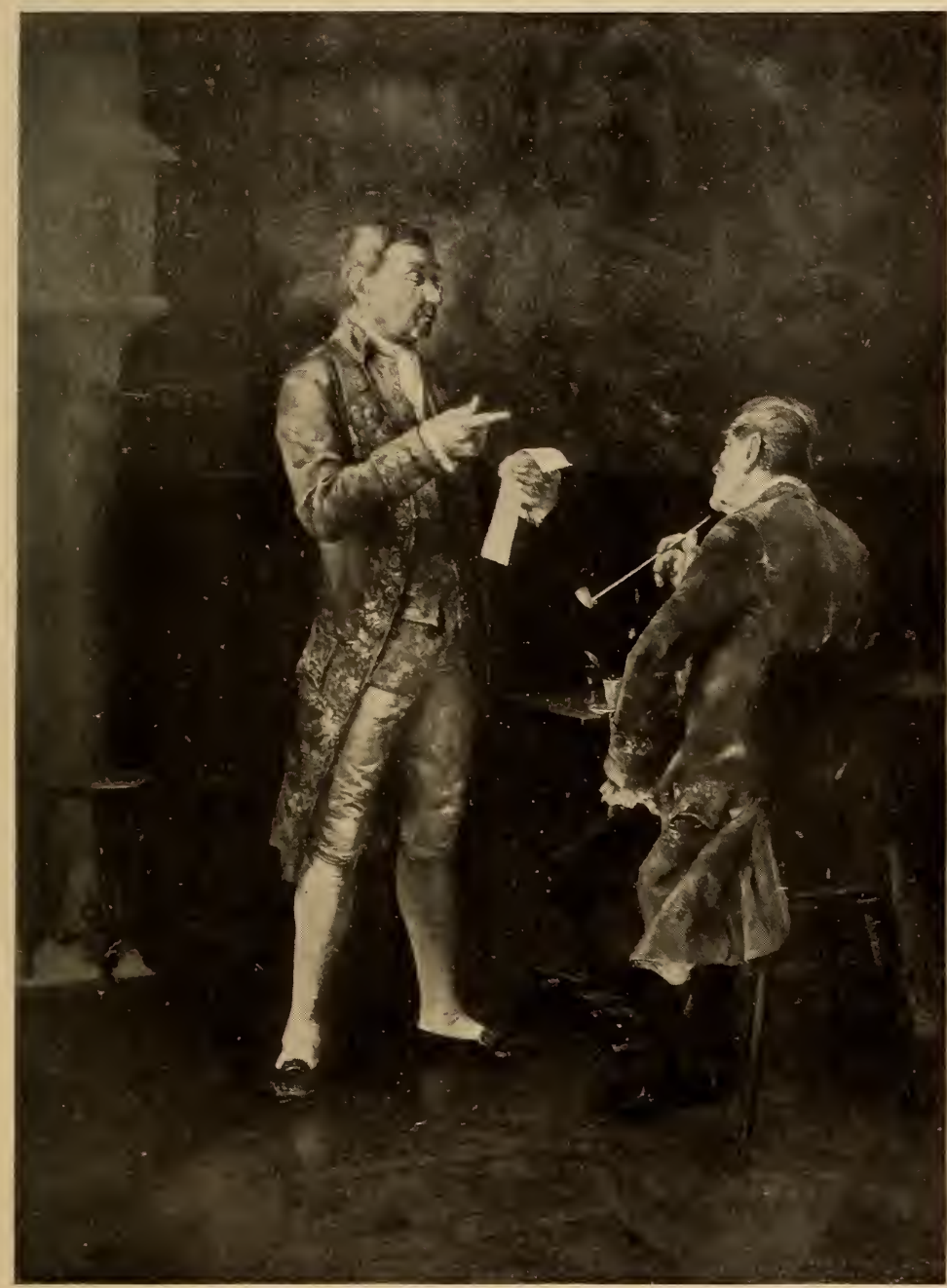

HARRY W. Watrous: L'ADDITION 



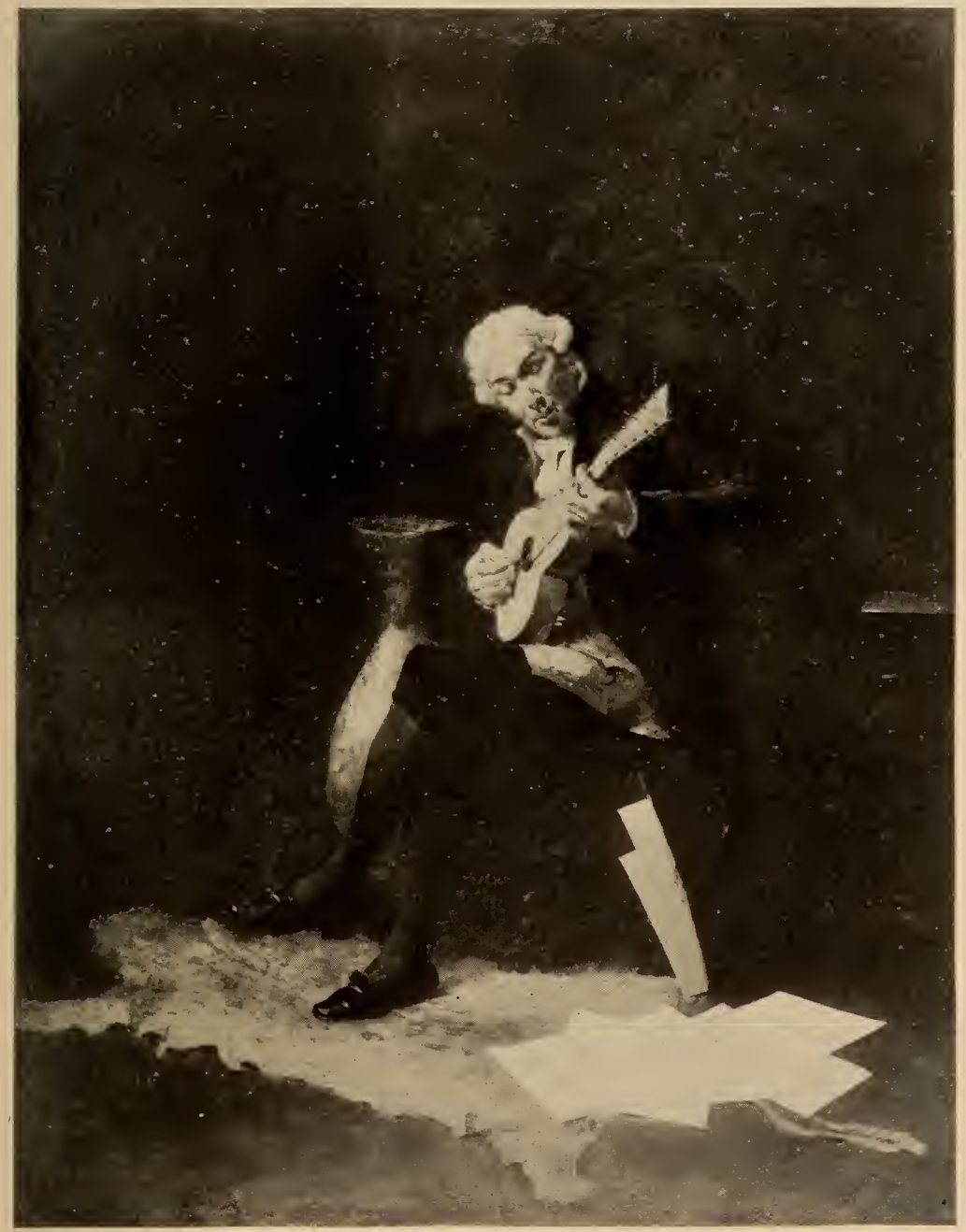

Harry W. Watrous: The Guitar Player 

of satins and of silks, the softness of furs and the richness of velvets, especially when it comes to doing it on a small canvas with the minute precision required in a picture that is intended to be seen at close range. Added to that task also is the further and greater one of an arrangement artistic in itself and interesting enough to intrigue the observer's attention; the final disposition of light and shadow and such a portrayal of facial expression as in the small figures of these cabinet paintings finally determine their meaning and therefore measure their importance and success as works of art.

The strain upon an artist's eyes in doing such miniature-like work is very great and in the case of Mr. Watrous effectually prevented his continuing it, having seriously affected his sight. He has however been fortunate enough to retain in his possession, or to acquire in later years, some of the best of the canvases of this kind which he painted in Paris long ago. He undoubtedly experiences now all of the pleasure in living with them that I felt upon seeing them for the first time in his home except, of course, the surprise of discovering something beautiful unknown to one before.

In an attempt to differentiate them and establish my preference among them I find that for exceptional handling of the light and shadow I incline to The Guitar Player, though in details of drawing and 
rendering of textures the subject does not quite equal the others. The expression of the old gentleman fingering the instrument is conspicuously successful in its portrayal of the intentness of the performer upon the rendering of his theme whatever it may be. The left arm should not be overlooked as an evidence of the painter's skill in handling a difficult pose.

For the picture called L'Addition the models were those of Meissonier and Vibert, the former's the seated figure and the latter's the one standing. Mr. Watrous tells with considerable glee of their reminiscences of these great painters and of their quarrels while he was at work upon this little canvas. Here again the faces are very expressive, but it will be noted that there is nothing of great difficulty or superior distinction in the poses, and the lighting is not unusual. The whole picture centres upon the representation of a commonplace enough incident and its merit lies in the fact that it is accomplished in a way that establishes its claim to consideration as a work of art, whereas a little less of fineness in any one of many details and it would sink to the level of a mere illustration.

In two other subjects, Records, and one entitled, Lost, there is an insistence upon the minutiae of this kind of painting that unhappily magnifies the more specifically technical and therefore less really im- 


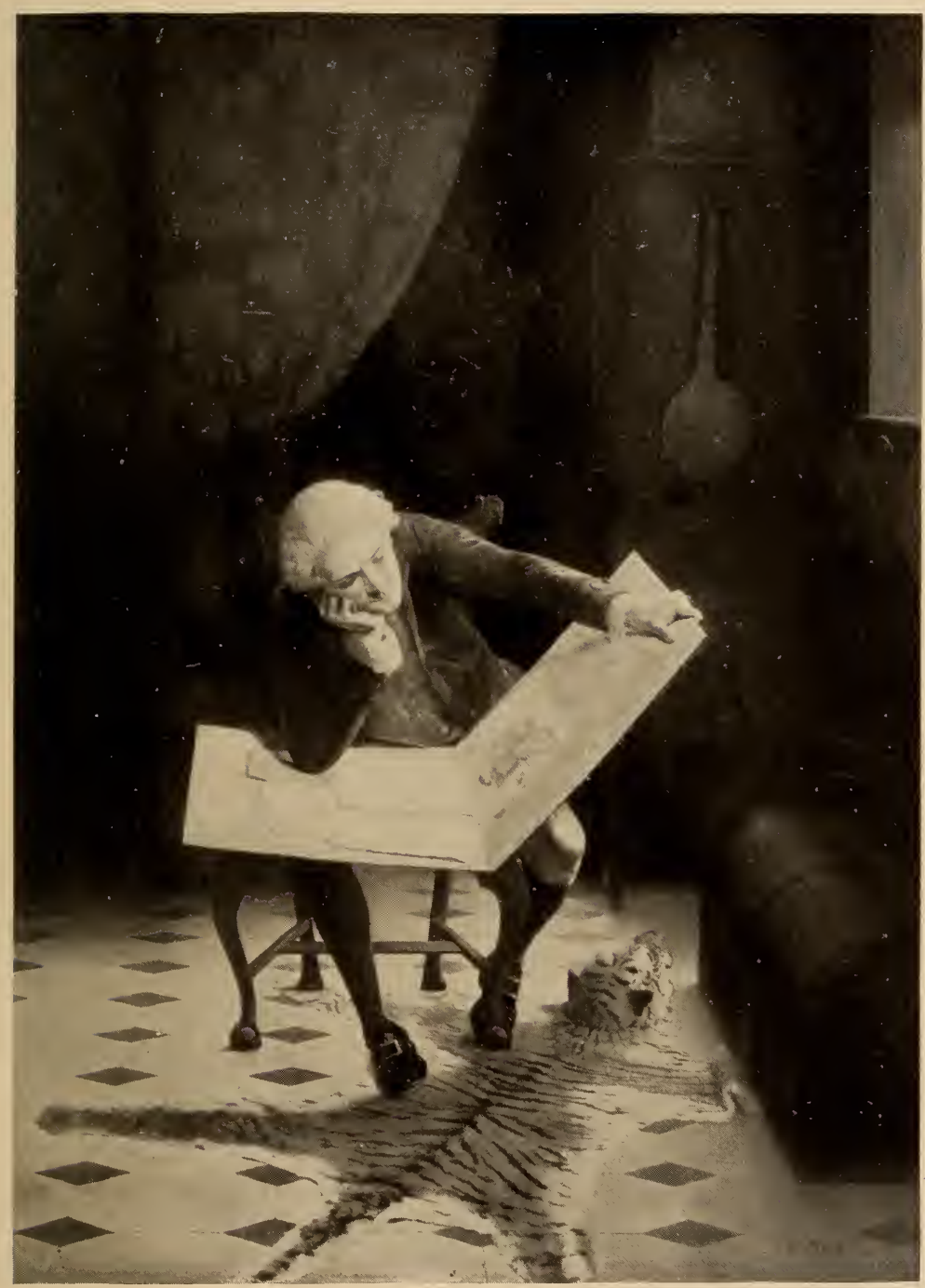

HaRRY W. Watrous: Records 



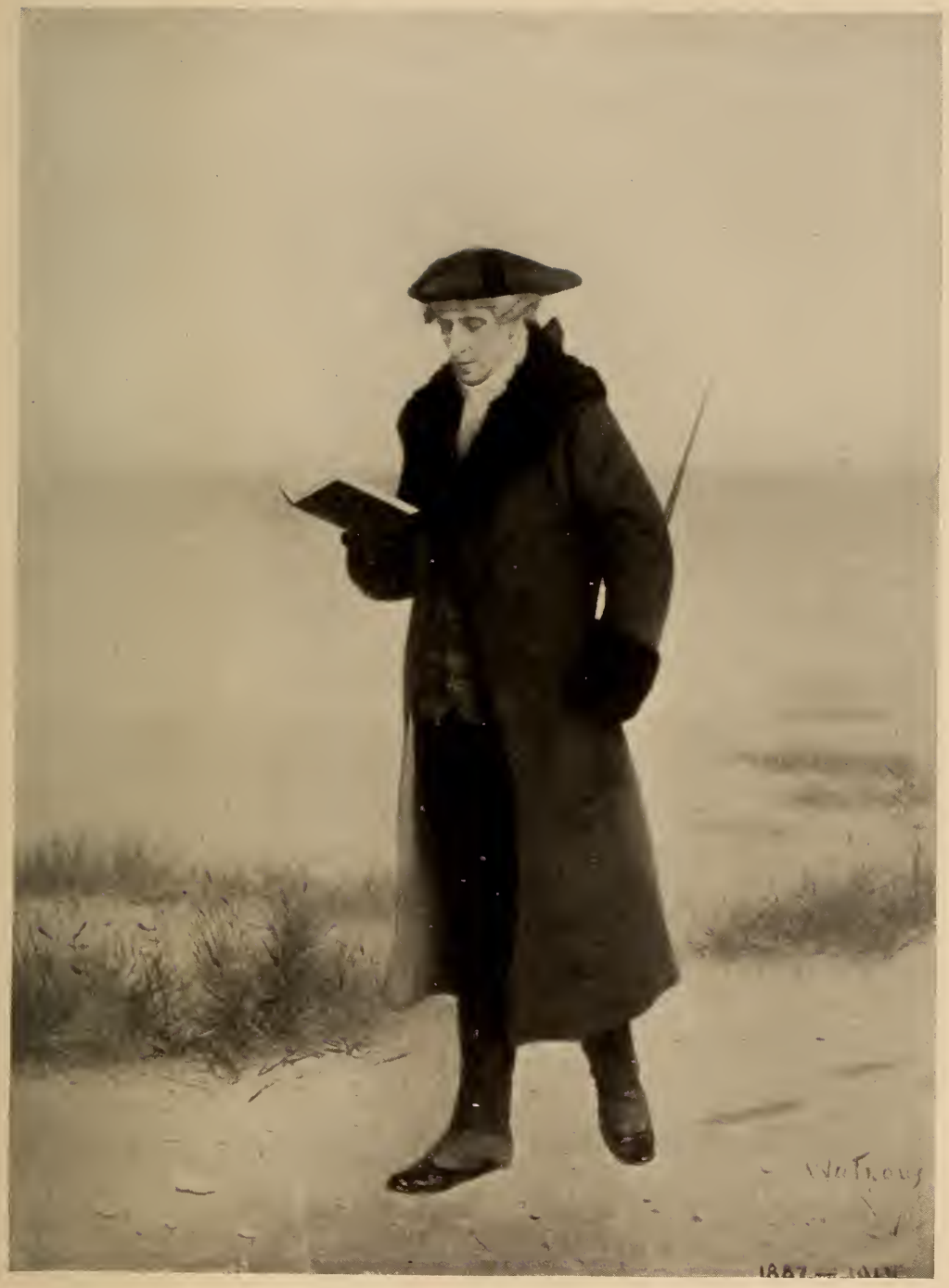

Harry W. Watrous: Lost 

portant elements that enter into it. In the former particularly the edges are hard and the light so strong as to reveal pitilessly the otherwise unimportant imperfections of the composition. The canvas called Lost is chiefly interesting for the fine rendering of the textures of the old gentleman's olive-green, furtrimmed great-coat, the red waistcoat showing beneath, and for being exceptionally happy in color as a whole. The gray sands of the shore in the foreground, the pale gray and blue of the water and the sky, form a most charming setting for the figure.

I saw elsewhere a year or two ago another of these early cabinet paintings by Mr. Watrous which I should like to be able to write about more fully than is possible out of a dimmed recollection of its actual appearance. It was called Mending the Fishing Rod and represented a middle-aged man seated on a low bench or stool, his legs spread wide and across his lap a fish-pole, over which he is bent at work, winding it with silk perhaps or fixing a guide ring for his line. A homely subject, it was treated with sincerity, and impressed me at the time as being a particularly successful performance.

In conclusion I must mention a very small oil painting, a portrait of his mother as an old lady, on a panel approximately three by five inches or so. It is one of the best pieces of portraiture "in little" that I know of in American art. I do not recall 
another that reproduces so accurately such an indication of old age as the pink of the little veins just under the transparent flesh of a face or, from a more comprehensive view, a more definite impression of a very real and lovable personality. 


\section{BENJAMIN WEST}





\section{BENJAMIN WEST}

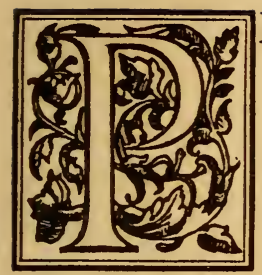

ERHAPS the unanimity with which the greatest of English painters responded toward the end of the eighteenth century to the scheme of John Boydell for forming a Shakespeare Gallery illustrates most forcibly the prevailing estimate of historic composition as the highest achievement in the realm of painting. Sir Joshua contributed a design for Macbeth, Romney one for The Tempest and both Benjamin West and Copley were represented. Romney as we now know always cherished the ambition of devoting all of his abilities to works of this description and writing to his friend Hayley in 1787 about the Shakespearean enterprise, he says: "This cursed portrait-painting! How I am shackled by it!" George Paston, in his late "Life" of the artist, remarks very pertinently that "Connoisseurs are inclined to give thanks that his love of depicting pretty faces and his desire to realize a competence interfered with his ambitious schemes."

Benjamin West, who, upon his arrival in England in 1763 , became almost at once a personality of consequence in art circles there, included among the 
canvases he sent to the Spring Gardens Exhibition of the year following a single portrait. He had, it seems, even then practically given up work in that particular field in which he had earned in his native land his first modest success, and it was not long thereafter that, as his first biographer, John Galt, records, "a series of circumstances placed him in that precise station in society where at the time there was the only chance of profitable employment as an historical painter." The reference, of course, is to West's favor with the King, for whom he painted almost exclusively during the period from $\mathbf{I} 768$ to I78I inclusive, producing a series of large religious and historical compositions for which, including several portraits and groups of the royal family, he received a total of over forty thousand pounds. While it is true that he is responsible for the substitution of realism in the historical painting of the time which was stultified by an absurd but generally approved fashion of representing figures always in the classic costume of antiquity, it is his misfortune to have been possessed by a passion for grandiose subjects and pictures of almost impossible dimensions.

As a youth in Philadelphia and New York, West began by painting portraits exclusively, and if the few he did in after years are any criterion of his early abilities he must have started out with a remarkable 


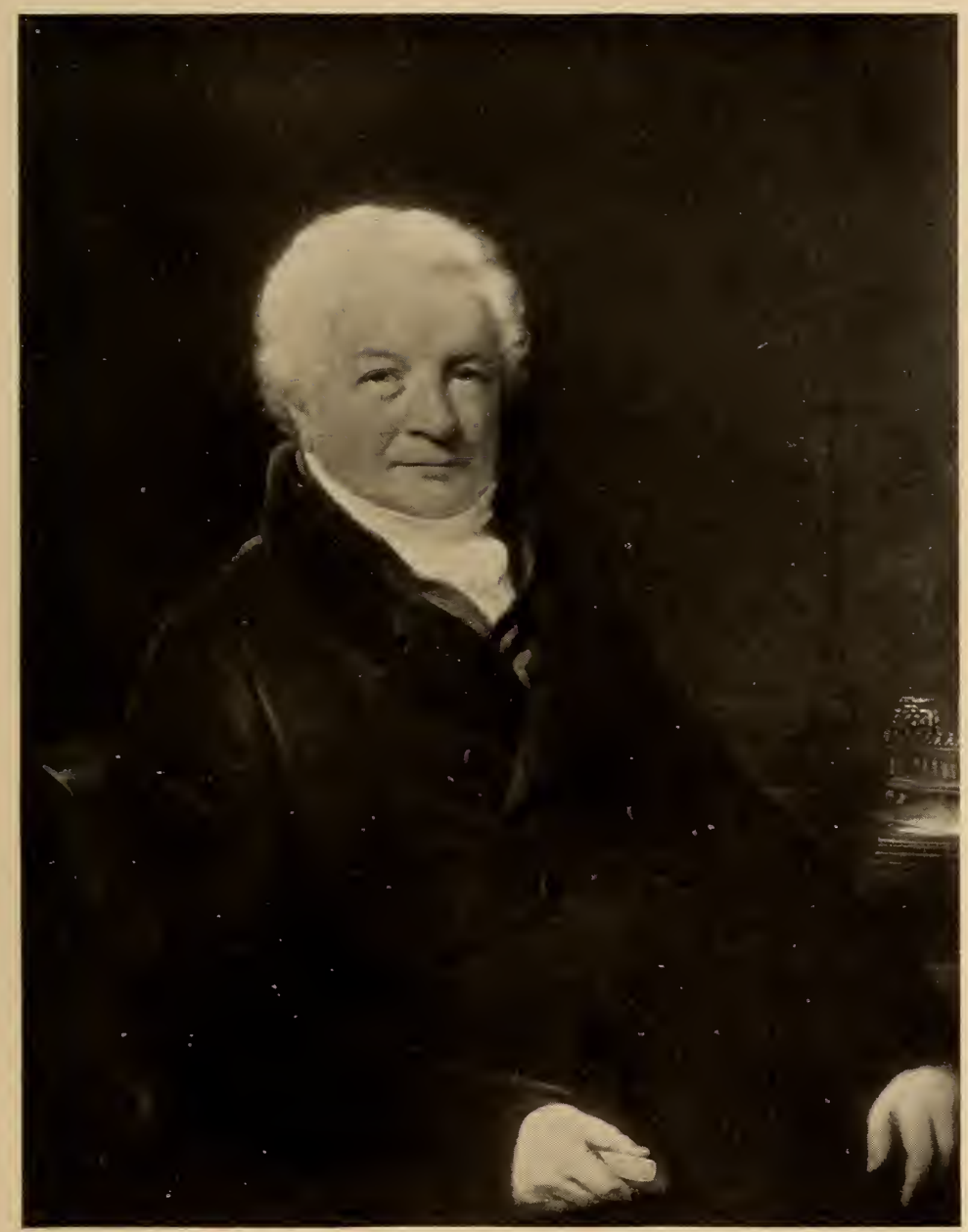

Benjamin West: John Sedley

Collection of Mr. Walter Jennings, New York 

aptitude for incorporating in his likenesses just those elusive indications of personality that are common to all that is notably true and fine in portraiture. It would not be possible to maintain that he was ever a great portrait-painter in the sense that several of his contemporaries unquestionably were, but it is quite evident that in the realm of male portraiture at least he was the equal of some of them.

One of the gratifying results of the present revival of interest in the early American portrait-painters is the fact that it has brought to our shores a number of excellent examples by West, acquainting us with that phase of his art which he almost entirely neglected at the height of his powers and during the period of his unprecedented popularity. Their suavity as well as their sincerity, their fine color as well as their technical excellence, inevitably persuade one that this was his proper field of artistic expression, and that the circumstances which permitted him to devote the best part of his life to the execution of elaborate tableaux that today are but little more than a memory in the minds of men, deprived his time and our own, as well as posterity, of any number of really fine portraits of men, for he was an indefatigable worker and consequently a prolific painter.

The John Sedley in the collection of Mr. Walter Jennings and another male portrait recently acquired by the Chicago Art Institute are fortunately both 
late works, the former being dated 1802 and the latter 1792. They belong to the limited series of commissions undertaken toward the end of his lifetime, but before his eye began to fail or his hand to falter and are excellent interpretations of character and convincing pieces of portraiture. The modelling of the features and the sensitive emphasis of individual expression in the faces are happily evident in the reproductions. No better illustrations of the artist's accomplishment in the way of portraiture are likely to be found. That he was content to adhere to established procedure in the posing of his sitters is of no particular consequence inasmuch as they are invariably represented in natural and dignified attitudes that never detract from the illusion of life. In the Brook Club in New York hangs his portrait group of Ralph Izard and his Friends. It is an attractive composition and a distinguished technical performance as well as being an interesting interpretation of nicely differentiated presentments of personality. West wisely eschewed in his portraiture any approach to that approximation of the dramatic in arrangement that is so considerable a factor in his historical and religious canvases, and specialized altogether upon the portrayal of personality as it is to be observed in the human countenance, translated by a momentary glance or a passing expression into an intelligible definition of character. 


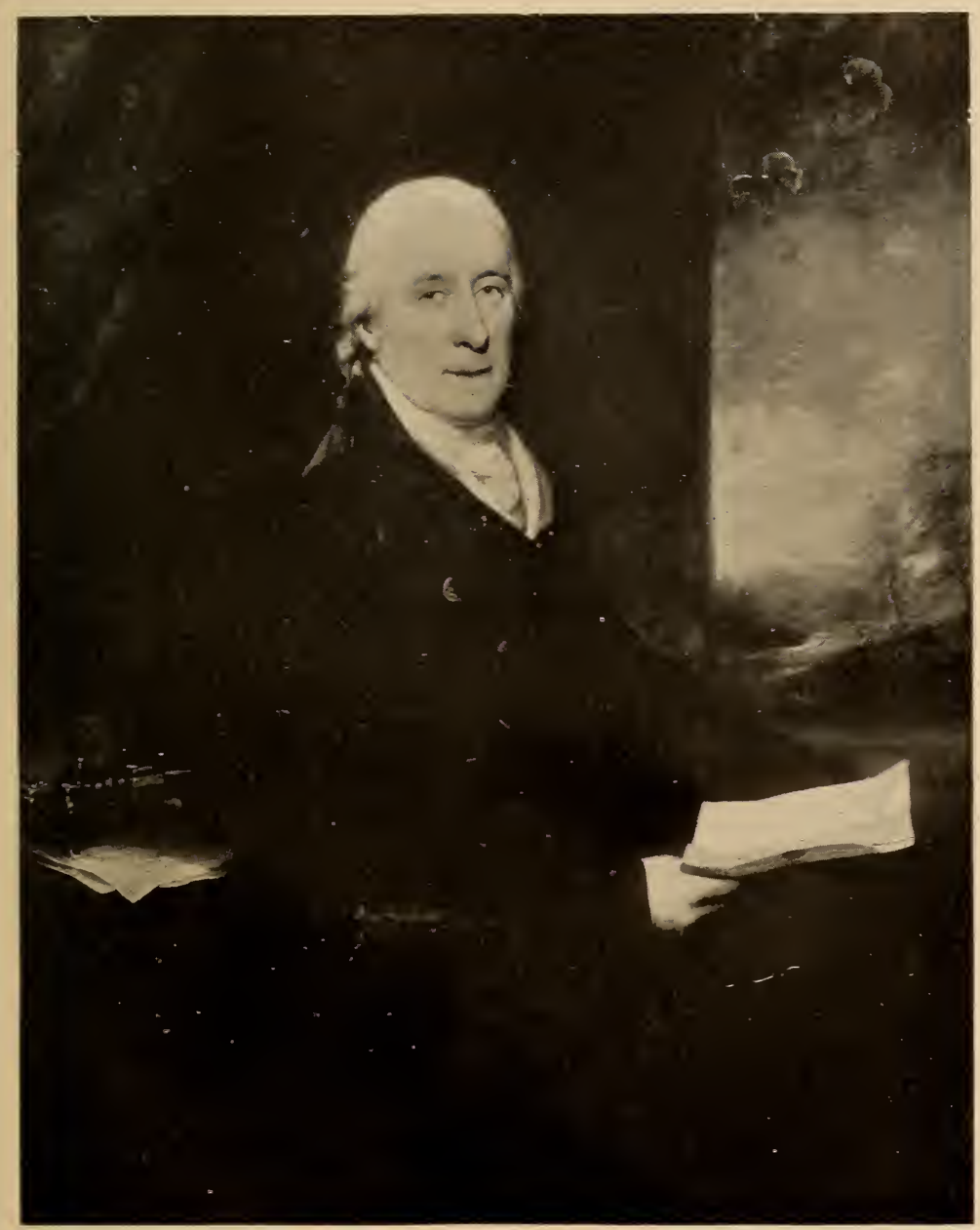

Benjamin West: Portrait of a Gentleman The Art Institute, Cbicago, Ill. 

Such of West's subject pictures as have recently been added to American collections are naturally those of modest size, a matter that we need not regret as they are finer examples than many of the more pretentious works. It is hardly necessary to say that the purity of his color and the excellence of his technic are just as apparent in them as in his portraits. The Envoys Returning from the Promised Land, in the Hackley Art Gallery, illustrates his capabilities and his limitations in this field. The forcibly and finely drawn figure of the warrior with the drawn sword at the right of the canvas alone meets the dramatic requirements of the scene. The others hardly emerge from the customary obscurity of the commonplace and even so only as the artist succeeds in investing one or another with some special charm of color or of pose. The women are noticeably oblivious in their pretty way of what is transpiring and the action and expression of even the more prominent of the remaining actors in the scene are quite unmistakably assumed and perfunctory. The resemblance of the warrior to a type familiar in Italian painting of the Renaissance, of the women to the prevailing type in eighteenth-century English art and of the Patriarch to a type common enough in Rembrandt's work, proves that West was very much of an eclectic and unhesitatingly adopted in his practice 
whatever of merit he found in the art of other men and other days.

In another historical composition, the Presentation of the Queen of Sheba at the Court of King Solomon, now at the Worcester Museum, the suggestion of Rembrandt occurs again in the turbaned figure at the right of the King, as well as more forcibly in whole general arrangement, grouping and lighting, of the canvas. The face of that one of the Queen's attendants facing the spectator and standing at the centre of those behind her, except for a certain softness and sweetness, somehow reminds one of the great Spaniard, Goya. The composition has an undeniable heroic quality and the lighting is notably effective. It would be an almost wholly satisfactory rendering of the subject did not the impressiveness of the moment suffer somewhat of an eclipse through the simpering fatuity of the various females. It is curious, by the way, that West, having introduced the style of painting personages of his own and immediately preceding ages in their proper costume should have persisted in the use of the costume of his own day in picturing scenes from antiquity. The women in this canvas and in the Hackley Art Gallery picture are dressed in the mode of eighteenthcentury England and thereby quite effectually prevent their perfectly realizing the effects intended. That they are not impressive in any such sense as 


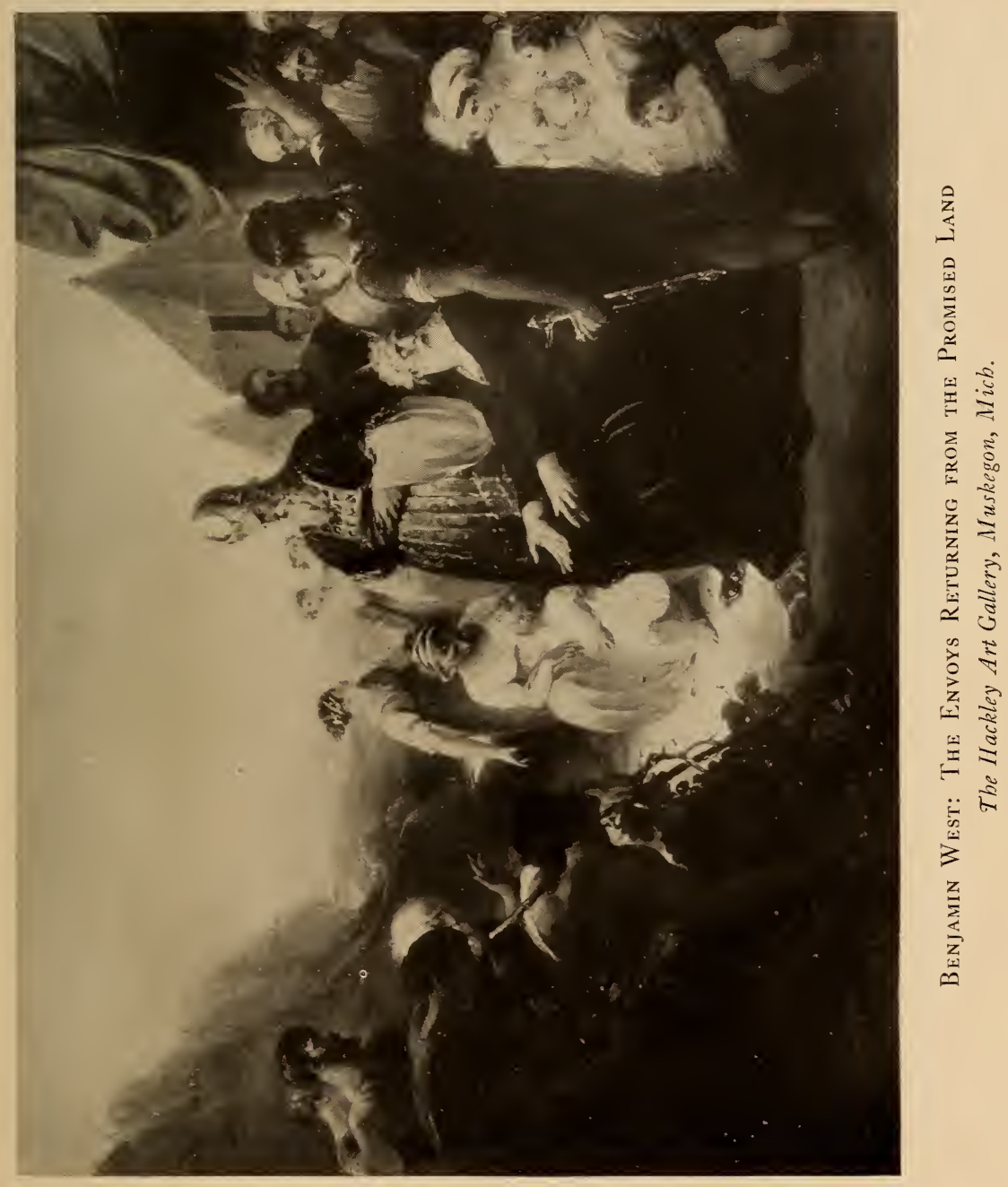





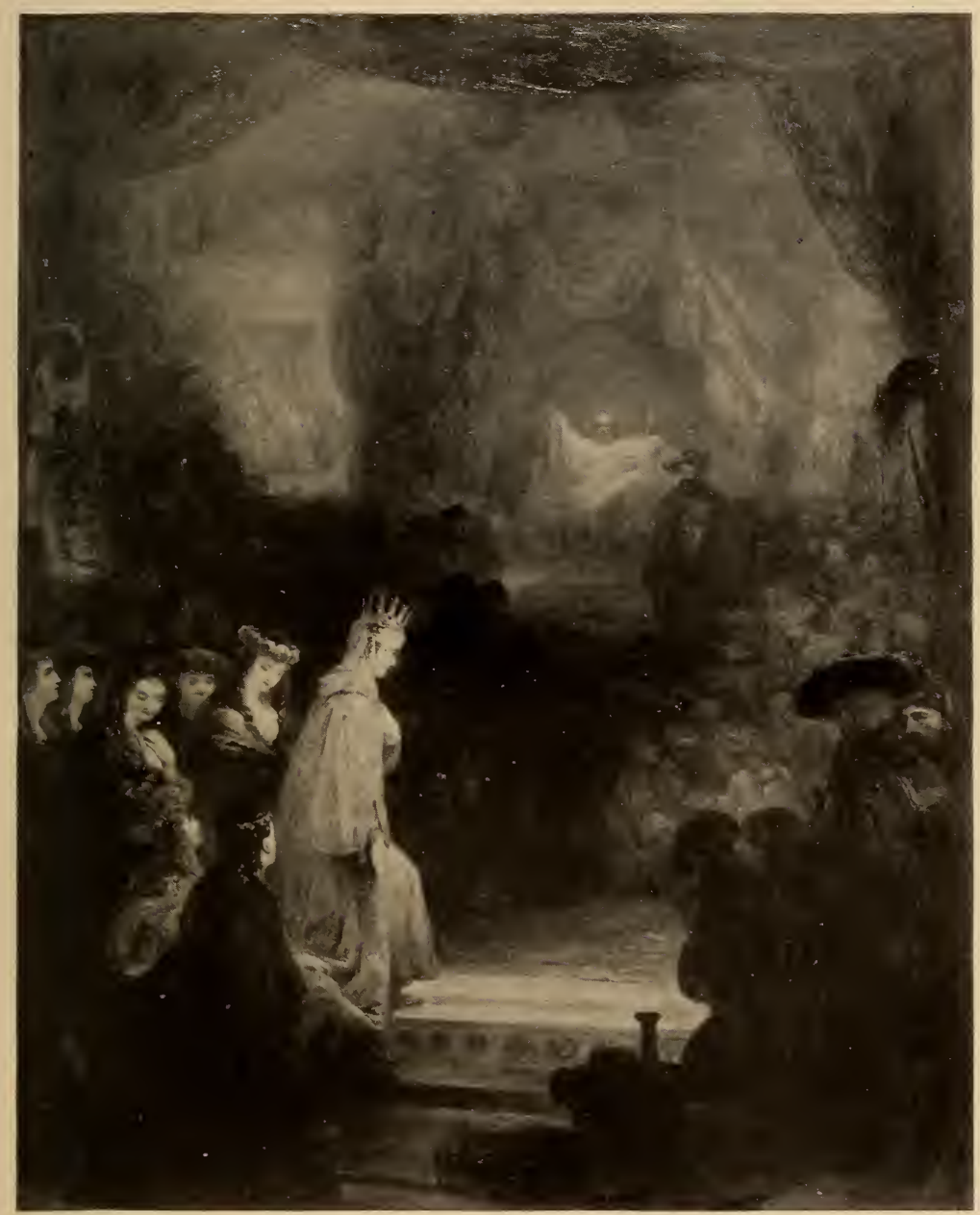

Benjamin West: Presentation of the Queen of Sheba at the Court of King Solomon Museum of Art, Worcester, Mass. 

they were intended is the conclusion that is forced upon one. As a matter of fact, however, none of the great artists of his time were any more successful in their efforts in this direction, and so far, at least, it is true that the preëminence of his position as a painter of such subjects was entirely justified by his performance which, though it is never entirely convincing, is yet very often punctuated by passages of real and definite distinction: Too much of the passion, the lust, the pathos of life, which never entered into the artist's experience, and which, never understanding, he was unable to picture, is missing for these canvases to sensibly stir us to any great enthusiasm. Lacking sufficiently dominant and compelling facial expressiveness to emphasize or explain their actions, his figures fail to properly sustain the dramatic possibilities of the scenes in which they appear. A great actor must perforce be a master of action and of both vocal and facial expression. In painting there being no possibility of representation of vocal expression the artist is forced into the necessity of realizing all of the possibilities of dramatic interpretation by such a delineation of bodily action and facial expression as will create a really significant and unforgettable picture of the humor, the pathos, or the tragedy of life. Only the greatest painters have ever succeeded in doing this. 

FIVE HUNDRED COPIES PRINTED DURING THE MONTH OF AUGUST, MCMXIX 




